\title{
Failure Mechanism and Numerical Simulation of Splitting Failure for Deep High Sidewall Cavern Under High Stress
}

Fan Li

Shandong University

Qiangyong Zhang ( $\square$ tianwailaike007@gmail.com )

Shandong University

Wen Xiang

Shandong University

Guangyuan Yu

Shandong University

\section{Research Article}

Keywords: High sidewall cavern, Geomechanical model test, Splitting failure, Strain gradient

Posted Date: March 11th, 2021

DOl: https://doi.org/10.21203/rs.3.rs-269014/v1

License: (a) (i) This work is licensed under a Creative Commons Attribution 4.0 International License. Read Full License

Version of Record: A version of this preprint was published at Geotechnical and Geological Engineering on June 15th, 2021. See the published version at https://doi.org/10.1007/s10706-021-01891-z. 


\section{Failure mechanism and numerical simulation of splitting failure for \\ 2 deep high sidewall cavern under high stress}

3 Fan $\mathrm{Li}^{\text {a }}$, Qiangyong Zhang ${ }^{\text {a,* }}$, Wen Xiang ${ }^{\mathrm{b}}$, Guangyuan $\mathrm{Yu}^{\mathrm{a}}$

$4 \quad{ }^{a}$ Research Center of Geotechnical and Structural Engineering, Shandong University, Jinan, China

$5 \quad{ }^{b}$ School of Qilu Transportation, Shandong University, Jinan, China

$6 \quad{ }^{*}$ Corresponding author: Qiangyong Zhang (email: qiangyongz@sdu.edu.cn)

7 Abstract: With the increase of the depth of the underground engineering, the phenomenon of

8 splitting failure of the deep rock will appear, which is very different from the shallow

9 cavern. In order to reveal the formation mechanism of splitting damage, mechanical model

10 tests and numerical simulations of splitting damage were carried out respectively. Using the

11 Pubugou Hydropower Station as the engineering background, a three-dimensional (3D)

12 geomechanical model test was conducted relying on a high stress three-dimensional load

13 test system. The splitting damage phenomenon of high sidewall cavern was observed, and

14 the oscillation variations of displacement and stress were measured. Based on strain

15 gradient theory and continuum damage mechanics, an elastic-plastic damage softening

16 model for splitting damage was established. The relationship between rock damage and

17 energy dissipation was analyzed. Based on the strain energy density theory, the splitting

18 damage criterion based on the strain gradient is established. A numerical analysis method

19 for splitting damage was proposed, and a regional disintegration calculation program was

20 developed based on a commercial finite element code. The numerical simulation results are

21 in basic agreement with the 3D geomechanical model test.

22 Keywords: High sidewall cavern; Geomechanical model test; Splitting failure; Strain

23 gradient 


\section{Introduction}

As a renewable energy source, hydropower has received increasing attention in China. Many large hydropower projects are under construction or have been completed. A series of complex discontinuous deformations were detected during the construction of these projects. This phenomenon poses a serious threat to the construction safety and long-term stability of high sidewall cavern. Among them, splitting failure is a special failure mode which is often encountered.

The splitting failure of cavern with high sidewall is an engineering failure phenomenon caused by the release of strain energy stored in rock mass due to excavation-induced unloading, which results in the initiation, expansion and penetration of cracks in surrounding rock. The splitting failure of hard rock has been extensively recorded and described by many researchers. Ortlepp et al. $(1994,1997)$ considered that splitting failure is a form of failure caused by excavation unloading under high geostress conditions. The splitting surface is generally parallel to the direction of maximum tangential stress. As the splitting failure develops, a v-shaped notch will eventually form. Martin et al. (2000) observed a field statistical analysis of 178 pillar failures in Canadian hard-rock mines. The study indicates that when the width-to-height ratio of hard rock pillars is less than 2.5 , the dominant failure mode is progressive slabbing and spalling which eventually leads to an hour-glass shape. Hibino (2001) and Yoshida et al. (2004) conducted on-site observations on 16 high sidewall caverns of the Japanese power system. Monitoring results show that the opening deformation of splitting cracks in the cavern accounted for a considerable part of the total deformation of the surrounding rock.

The damage mechanics method has good applicability to simulate the stiffness 
degradation and strain softening characteristics of rock materials, and can simulate the nonlinear behavior of rock materials after the peak more comprehensively to be widely used in investigating the failure responses of rock caverns. Li et al. (2013) applied elastic damage mechanics to model the softening behavior of rock masses. Then they proposed a numerical method based on the maximum tensile stress criterion and strain energy density theory to simulate the zonal fracture phenomenon. Tao et al. (2013) applied a damage formulation to simulate softening and modulus reduction to propose a new method to understand the mechanisms and behaviors of high initial stress rocks. Jia et al. (2012) studied the damage evolution around deep underground openings under multiaxial stress through 3D numerical tests. The results show that biaxial stress parallel to the free surface constrained by zero or low confinement stress contributes to spalling or parallel fracture of the slab.

According to the classical continuum theory, the stress at a point of the material is only a function of the strain and deformation history at that point, independent of the strain in the region of the adjacent zone. However, the classical continuum theory is not strictly satisfied due to the imperfect nature of the rock material. The strain gradient effect does not control the deformation and strength of geotechnical materials in their elastic phase, but when the material reaches its peak strength, the strain gradient becomes large to become the cause of

65 strain localization initiation and development. In recent years, the strain gradient theory that introduces internal length parameters of materials has gradually been developed as a non-local theory. Strain gradient theory can be used to describe the local and post-peak strain softening of rock (Steinmann, 1994; Zbib and Aifantis, 1988a and 1988b). The local strain in the rock is usually accompanied by strain softening. It is precisely because the influence of strain gradient is ignored that the previous numerical analysis methods are difficult to explain

71 the problems of splitting failure (Zhang et al., 2017). Based on the strain gradient theory and 72 plastic deformation theory, Gao et al. (2019) established the elastic-plastic damage softening 
model and elaborated the formation mechanism and development law of ZDP.

With its advantages of visualization, intuition and realism, the geomechanical model test is of great significance to the study of damage mechanism of underground caverns (Chen et al. 2013a, 2013b and 2013c; Zhang et al. 2013 and 2017; Gao et al. 2018). The method can also simulate excavation and unloading under real three-dimensional high ground stress conditions, reproduce the damage pattern of the cavern, and capture the variations in deformation and stress (Zhang et al., 2019a, 2019b).

Although great progress has been made in studying the microscopic mechanisms of rock specimens (Tang et al., 2001; Liu et al., 2002; Fang et al., 2002; Sahouryeh et al., 2002; Dyskin et al., 2003), laboratory or field experiments (Bauch et al., 2004; Wong et al., 2004; Li et al., 2011; Jiang et al., 2017; Liu et al., 2017; Gong et al., 2012; Gong et al., 2018) and numerical simulations (Zhu et al., 2010; Wang et al., 2016; Sharif et al., 2019; Wowk et al., 2019), so far there is no widely accepted theoretical explanation for splitting failure, and further improvement of theoretical methods is still needed. In this paper, the 3D geomechanical model test of splitting failure is firstly introduced, and the variations of displacement and stress around the high sidewall cavern are given. Based on the strain gradient theory and continuous damage theory, an elastic-plastic damage model for splitting failure is established. According to the strain energy density theory, the energy damage criterion for splitting failure is proposed. In order to consider the strain gradient effect in the numerical simulation, a high-order hexahedral cell is constructed using Hermite interpolation function, and the shape function and stiffness matrix of the cell are derived. The numerical analysis method of regional rupture was proposed, and the corresponding calculation program was developed based on the ABAQUS platform. The results of numerical simulations and model tests are in general agreement. The reliability of the damage softening model and the numerical analysis method of regional rupture are proved. Finally, on the basis of theoretical 
analysis and numerical simulation, the formation mechanism of deep high sidewall cavern splitting failure is described.

\section{Three dimensional geomechanical model test}

\subsection{The scheme of the geo-mechanical model}

We take the main powerhouse project of the Pubugou Hydropower Station as the engineering background. The underground powerhouse cavern is located in the granite rock mass on the left bank downstream of the dam axis. The overlying rock thickness is $360 \mathrm{~m}$, and cross-section size of the main powerhouse is $26.8 \mathrm{~m} \times 70.1 \mathrm{~m}$. According to the similarity principle (Zhang et al. (2019c)) and considering the scale of the main powerhouse and the size of the test system $(0.7 \mathrm{~m} \times 0.7 \mathrm{~m} \times 0.7 \mathrm{~m})$, the geometrical similarity of the model test is selected as $C_{L}=C_{P} / C_{M}=300$. The extent and in-situ stress simulated by the model test are shown in Fig. 1.

We chose IBSCM (iron-barites-silica cementation material) as the analogous material (Zhang et al. (2019)). The physical and mechanical parameters of the granite and the analogous material and its mixture proportion are provided in Tables 1 and 2, respectively. Fig. 2a shows the three typical monitoring sections to accurately reflect the deformation and stress changes of surrounding rock during the testing, in which section I and III are stress monitoring sections, and section II is deformation monitoring section. As shown in Fig. 2b, five measuring lines are arranged for each monitoring section, and each measuring line is arranged with six measuring points. Due to the size of the model, in the vertical measurement Line $\mathrm{C}$ is arranged five measuring points.

\subsection{Construction, excavation and overloading of the geo-mechanical model}


model is paved, compacted and air-dried layer by layer. (Zhang et al. 2017). The body of the model is divided into 10 layers of $70 \mathrm{~mm}$ each. When the design elevation is reached, the grooves are cut and the measuring sensors are buried. To avoid delamination at the adjacent interfaces of the model, the surface of the previous layer of material must be chiselled rough and moistened with alcohol before the next layer is constructed.

Boundary loads were applied to the model using a 3D loading system (Figure 3). The model body was loaded in increments of 0.1 times the original ground stress until the design value was reached. After the design stress was reached, the load was held constant for $24 \mathrm{~h}$ to produce an initial stress field in the model that was consistent with the original stress field. Due to the limitations of the cavern dimensions, the nine excavation levels were combined into three layers in the actual project, as shown in Fig. 4. Each layer was excavated in 17 steps, each with an excavation length of $40 \mathrm{~mm}$ (equivalent to $12 \mathrm{~m}$ in the prototype). When the excavation of one footage was completed, the excavation was paused and the data was observed. When the data monitored by the sensors is stable, the next step of excavation is started until the entire excavation is completed. Once the cave excavation is complete, the load is held constant until the monitored data is stable and then recorded.

\subsection{Model test results}

As shown in Fig. 5, the wall of high sidewall cavern is seriously damaged. There are significant longitudinal splitting cracks on both sides of the model cavern, but no obvious damage to the vault. This is a typical damage of splitting failure in high sidewall cavern. The length of the cracks near the high sidewalls is slightly less than the height of the sidewalls. The farther away from the sidewall, the shorter the cracks are. The distance from the outermost crack to the sidewall is about $20.8 \mathrm{~m}$, which is consistent with the measured data at the project site. 
In this section, all the model test results have been converted to the prototype according to the principles of similitude. After excavation, the deformation of the cavern perimeter all developed toward the cavern (Fig. 6). The displacement of the nearest measurement point is relatively large, indicating that the area close to the cavern wall is a fractured area of the surrounding rock in the traditional sense, which is consistent with the damage of the

151 from the cavern sidewall is much smaller than that of other measurement points on the line,

152 indicating that the excavation disturbance in the high sidewall cavern at $3 L$ from the cavern 153 has almost no effect. The displacements at the sidewalls show oscillatory attenuation, which 154 is completely different from the variation of displacements around the shallow cavern. The 155 displacements at the vaults all show a monotonic decay trend, which is completely different from that at the sidewalls.

After excavation, due to the stress release around the high sidewall cavern chamber, the deformation was all toward the cavern, and the radial stress around the cavern decreased (Fig.

159 7). With the increase of the distance from the side wall of the cavern, the damage of the 160 surrounding rock decreases. The change in radial stress is consistent with the radial 161 displacement. The tangential stress variation shown in Fig. 8 is relatively different from the 162 displacement and radial stress variation. The tangential stresses here are close to zero due to 163 severe damage near the high sidewalls resulting in stress relief. Then the tangential stress 164 increases gradually with distance until it reaches a maximum at $L$. Since the maximum 165 tangential stress shifts from the periphery of the cavern wall to the junction of the 166 elastic-plastic zone when the surrounding rock enters the plastic state. It means that the 167 surrounding rock in the range of $L$ is in a plastic state. The surrounding rock in the range of $L$ 168 to $3 L$ is in the elastic state, and the fluctuation of oscillatory attenuation is small, and the 169 variation between two adjacent points is about $15 \%$. 


\subsection{Virtual working principle and control equation}

In Toupin-Mindlin strain gradient theory, in order to describe the state of a material, in

173 addition to Euler strain tensor $\varepsilon_{i j}$ and Cauchy stress tensor $\sigma_{i j}$, strain gradient term $\eta_{i j k}$

174 and the higher order stress tensor $\tau_{i j k}$ are also needed (Zhang et al., 2017). The expressions

175 of Euler strain and strain gradient are as follows:

$$
\varepsilon_{i j}=\left(u_{i, j}+u_{j, i}\right) / 2, \quad \eta_{i j k}=\left(u_{k, i j}+u_{k, j i}\right) / 2
$$

In the above equation, both the Eulerian strain $\varepsilon_{i j}$ and the strain gradient $\eta_{i j k}$ are symmetric tensors, as are the corresponding Cauchy stress $\sigma_{i j}$ and higher order stress $\tau_{i j k}$. It is further assumed that the strain rate and strain gradient rate can be decomposed into elastic part and plastic part respectively:

$$
\&=\&
$$
2004), it is assumed that the plastic strain gradient contributes to the work per unit volume.

185 Therefore, the principle of virtual work should include the work contribution of elastic strain 186 and the work done by plastic strain and its gradient. The virtual work $\delta W_{i}$ of internal unit 187 volume $V$ can be expressed as:

$$
\delta W_{i}=\int_{V}\left(\sigma_{i j} \delta \varepsilon_{i j}^{e}+q_{i j} \delta \varepsilon_{i j}^{p}+\tau_{i j k} \delta \varepsilon_{i j, k}^{p}\right) \mathrm{d} V
$$
strain $\varepsilon_{i j}^{p} ; \tau_{i j k}$ denotes the higher-order stress tensor, which is conjugate to the work of the 
192

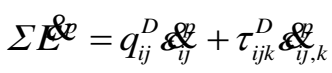

contributes to the virtual work $\delta W_{i}$. Therefore, $q_{i j}$ and $\tau_{i j k}$ in this paper are the omission of $q_{i j}^{\prime}$ and $\tau_{i j k}^{\prime}$ respectively. The Eq. (3) can be expressed as follows:

$$
\delta W_{i}=\int_{V}\left(\sigma_{i j} \varepsilon_{i j}+\left(q_{i j}-\sigma_{i j}^{\prime}\right) \delta \varepsilon_{i j}^{p}+\tau_{i j k} \delta \varepsilon_{i j, k}^{p}\right) \mathrm{d} V
$$

Then the following formula can be obtained by applying Gauss' theorem:

$$
\delta W_{i}=\int_{S}\left(\sigma_{i j} n_{j} \delta u_{i}+\tau_{i j k} n_{k} \delta \varepsilon_{i j}^{p}\right) \mathrm{d} S-\int_{V}\left[\sigma_{i j, j} \delta u_{i}+\left(\tau_{i j k, k}+\sigma^{\prime}-q_{i j}\right) \delta \varepsilon_{i j}^{p}\right] \mathrm{d} V
$$

where $n_{i}$ is the normal vector outward in the direction of the surface $S$. Eq. (3) should be valid for any change in displacement and plastic strain. The first integral on the right side of Eq. (5) can be identified as external virtual work. The second integral on the right side of Eq. (5) should be vanished with arbitrary variations, so two sets of equilibrium equation can be determined:

$$
\left\{\begin{array}{l}
\sigma_{i j, j}=0 \\
\tau_{i j, k}+\sigma_{i j}^{\prime}-q_{i j}=0
\end{array}\right.
$$

Then, the corresponding conventional $T_{i}=\sigma_{i j} n_{j}$ and higher order $t_{i j}=\tau_{i j k} n_{k}$ boundary conditions can be obtained according to the principle of virtual work.

\subsection{Constitutive equation}

In a thermodynamically consistent manner, the dissipative work generated by higher-order strains is introduced by employing higher-order stress related to strain increments (Gudmundson, 2004; Gurtin and Anand, 2005). The key step in constructing such a constitutive equation is to define the effective stress $\Sigma$ work conjugated with the gradient-enhanced effective plastic strain rate $E^{\&}$ to ensure the plastic work rate: 
can be defined as:

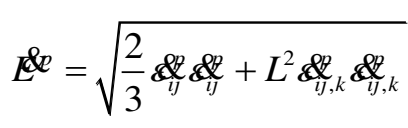

where $L$ is the dissipative length scale. Thus, the effective stress can be defined as:

$$
\Sigma=\sqrt{\frac{2}{3} q_{i j}^{D} q_{i j}^{D}+L^{-2} \tau_{i j k}^{D} \tau_{i j k}^{D}}
$$

Then the dissipative plastic micro-stress tensor and dissipative plastic high-order stress tensor can be easily obtained:

$$
q_{i j}^{D}=\frac{2}{3} \frac{\Sigma}{E^{\&}} \underset{i j}{\&}, \quad \tau_{i j k}^{D}=\frac{\Sigma}{E^{\&}} L^{2} \underset{i, k}{\& 2}
$$

as:

$$
\begin{aligned}
& W=\Psi-\Phi= \\
& \frac{1}{2}\left(\varepsilon_{i j}-\varepsilon_{i j}^{p}\right) C_{i j k l}^{e d}\left(\varepsilon_{k l}-\varepsilon_{k l}^{p}\right)+\frac{1}{2} \eta_{i j k}^{e} \Lambda_{i j k l m n} \eta_{l m n}^{e}+\frac{1}{2} \varepsilon_{i j}^{p} C_{i j k l}^{p d} \varepsilon_{k l}^{p}+\frac{1}{2} G l^{2} \eta_{i j k}^{p} \eta_{i j k}^{p} \\
& -\sqrt{\frac{2}{3} \underset{i j}{\mathrm{~g}} \underset{i j}{\mathrm{~g}}+L^{2} \underset{i,, k}{\mathrm{~g}} \underset{i,, k}{\mathrm{~g}}} \sqrt{\frac{2}{3} q_{i j}^{D} q_{i j}^{D}+L^{-2} \tau_{i j k}^{D} \tau_{i j k}^{D}}
\end{aligned}
$$

where $C_{i j k l}^{e d}$ is elastic damage tensor and is a fourth-order tensor, $C_{i j k l}^{e d}=(1-d) C_{i j k l}^{e}$;

$225 \Lambda_{i j k l m n}$ is elastic damage tensor considering strain gradients and is a six-order tensor, $\Lambda_{i j k l m n}=(1-d) l^{2} C_{i j l m}^{e} \delta_{k n} ; \quad C_{i j k l}^{p d}$ is plastic damage tensor and is a fourth-order tensor, $C_{i j k l}^{p d}=\left(1-D+\delta_{i j} D / 3\right) C_{i j k l}^{p} ; G$ is the shear modulus, $G=(1-d) E /[2(1+v)] ; \quad l$ is the internal length parameter of the material, which is closely related to the microcracks and microdefects inside the material and is an inherent property of the material; $\delta_{k n}$ is a

230 Kronecker symbol. In the above parameters, $D$ is the modified damage variable, $D=\delta d$, $231 \delta$ is the damage variable correction parameter or initial damage number; $d$ is the damage 
variable. In this paper, the damage evolution law is selected to describe the mechanical properties of rock under high in-suit stress. It is considered that there is no damage in the material of elastic state, and damage begins to appear in the plastic state when the rock yield. The expression of damage evolution equation is as follows:

$$
d=1-\frac{\kappa_{i}}{\kappa}\left[(1-\alpha)+\alpha e^{-\beta\left(\kappa-\kappa_{i}\right)}\right]
$$

where $\kappa_{i}$ indicates the threshold for damage initiation; $\alpha$ and $\beta$ are material matrix expression is:

$$
C_{i j l m}^{e}=\left[\begin{array}{cccccc}
\frac{E(1-v)}{(1+v)(1-2 v)} & \frac{E v}{(1+v)(1-2 v)} & \frac{E v}{(1+v)(1-2 v)} & 0 & 0 & 0 \\
\frac{E v}{(1+v)(1-2 v)} & \frac{E(1-v)}{(1+v)(1-2 v)} & \frac{E v}{(1+v)(1-2 v)} & 0 & 0 & 0 \\
\frac{E v}{(1+v)(1-2 v)} & \frac{E v}{(1+v)(1-2 v)} & \frac{E(1-v)}{(1+v)(1-2 v)} & 0 & 0 & 0 \\
0 & 0 & 0 & \frac{E}{2(1+v)} & 0 & 0 \\
0 & 0 & 0 & 0 & \frac{E}{2(1+v)} & 0 \\
0 & 0 & 0 & 0 & 0 & \frac{E}{2(1+v)}
\end{array}\right]
$$

tensor $\mathbf{C}^{p}$ can take the following form:

$$
\mathbf{C}^{p}=\frac{\mathbf{C}^{e} \frac{\partial g}{\partial \boldsymbol{\sigma}}\left(\frac{\partial f}{\partial \boldsymbol{\sigma}}\right)^{T} \mathbf{C}^{e}}{\left(\frac{\partial f}{\partial \boldsymbol{\sigma}}\right)^{T} \mathbf{C}^{e} \frac{\partial g}{\partial \boldsymbol{\sigma}}-\frac{\partial f}{\partial H}\left(\frac{\partial H}{\partial \boldsymbol{\varepsilon}^{p}}\right)^{T} \frac{\partial g}{\partial \boldsymbol{\sigma}}}
$$

where $H$ is the hardening function, which is a function of plastic strain. In order to reflect the characteristics of plastic hardening and plastic softening of rock materials (Fig. 9), its expression form takes the following exponential form: 


$$
H=H\left(\varepsilon_{i j}^{p}\right)=k_{1} \varepsilon_{i j}^{p} \exp \left(k_{2} I_{1}-k_{3} \varepsilon_{i j}^{p}\right)
$$

where $k_{i}(i=1,2,3)$ is the material parameter; $I_{l}$ is the first stress invariant, which can represent the average stress or hydrostatic stress. The $f$ and $g$ in Eq. (14) are the yield function and the plastic potential function, respectively. Considering the influence of the intermediate principal stress, the yield function $f$ and plastic potential function $g$ constructed based on the Drucker-Prager strength criterion are as follows:

$$
\left\{\begin{array}{l}
f=f(\boldsymbol{\sigma}, H)=\alpha I_{1}(\boldsymbol{\sigma})+\sqrt{J_{2}(s)}-(1-d) H\left(\varepsilon_{i j}^{p}\right) \\
g=g(\boldsymbol{\sigma}, H)=\beta I_{1}(\boldsymbol{\sigma})+\sqrt{J_{2}(s)}-(1-d) H\left(\varepsilon_{i j}^{p}\right)
\end{array}\right.
$$

where $J_{2}$ is the second invariant of stress deviation; $\alpha$ and $\beta$ are intensity parameters,

and their expressions are as follows:

$$
\left\{\begin{array}{l}
\alpha=\frac{2 \sin \varphi}{\sqrt{3}(3-2 \sin \varphi)} \\
\alpha=\frac{2 \sin \psi}{\sqrt{3}(3-2 \sin \psi)}
\end{array}\right.
$$

where $\varphi$ and $\psi$ represent the friction angle and expansion angle of the rock, respectively. When $\varphi=\psi$, that is, $\alpha=\beta$, it is the associated flow law. tensor can be derived from the free energy function strain and strain gradient respectively:

$$
\sigma_{i j}=\left\{\begin{array}{l}
C_{i j k l}^{e} \varepsilon_{k l}^{e} \\
\left(1-D+\delta_{i j} D / 3\right) C_{i j k l}^{p} \varepsilon_{k l}^{p}-\frac{2}{3} \frac{\Sigma}{E^{p}} \varepsilon_{k l}^{p}
\end{array}\right.
$$

$$
\tau_{i j k}=\left\{\begin{array}{l}
l^{2} C_{i j k l}^{e} \delta_{m n} \eta_{l m n} \\
\frac{(1-D) C_{i j k l}^{p}}{2(1+v)} l^{2} n_{i j k}^{p}-\frac{\Sigma}{E^{p}} l^{2} \varepsilon_{k l}^{p}
\end{array}\right.
$$


The deformation damage of rocks is essentially a damage evolution process of energy dissipation, so it will be easier to reflect the characteristics of the mechanical response of rocks by studying the relationship between the energy change law and rock damage during the damage damage process. The damage of rocks is a process of progressive deterioration of materials due to the gradual increase of damage, and microscopic cracks are generated and expanded until penetration. Therefore, the study of rock rupture from the perspective of microscopic mechanics, the analysis of the damage damage law of tiny units of rocks, and the study of unit damage through the unit energy dissipation and energy discrimination criteria can show the whole process of rock rupture in a more systematic and complete way. criterion for determining whether damage has occurred in rocks needs to be given. Based on the damage characteristics of the material and the different loading conditions, many different

277 damage criteria have been proposed, which can generally be divided into four main categories:

278 stress or strain-based damage criteria, energy-based damage criteria, damage-based damage 279 criteria and empirical damage criteria. In essence, the deformation and damage of rocks is a 280 process of continuous energy dissipation, therefore, if the energy change in the process of rock damage can be studied in depth, the strength criterion based on the energy change will be able to describe the process and mechanism of rock damage more accurately.

\subsection{Element failure criterion}

In order to obtain the distribution of failure zone in the surrounding rock, it is necessary to give a criterion to determine the failure of element. In the numerical simulation, two criteria are used to determine the failure of elements: maximum tensile strain criterion and 
according to Eq. (20). If the maximum tensile strain $\varepsilon_{\max }$ is greater than or equal to the ultimate tensile strain $\varepsilon_{t u}$, the element is subjected to tensile failure. In order to maintain the integrity and continuity of the entire calculation during the numerical simulation, a small residual elastic modulus $E_{C}$ ( $E_{C}=0.05 E, E$ is elastic modulus) is applied to the rock mass element where the tensile failure occurs.

$$
\varepsilon_{\max }=\frac{2}{\sqrt{3}} \sqrt{\left|J_{2}{ }^{\prime}\right|} \cos \left(\omega-\frac{\pi}{3}\right)+\frac{I_{1}{ }^{\prime}}{3}
$$

where

$$
\omega=\frac{1}{3} \arccos \left(-\frac{3 \sqrt{3}}{2} \frac{J_{3}{ }^{\prime}}{\left|J_{2}{ }^{\prime}\right| \sqrt{\left|J_{2}{ }^{\prime}\right|}}\right)
$$

$$
\left\{\begin{array}{l}
I_{1}{ }^{\prime}=\varepsilon_{x}+\varepsilon_{y}+\varepsilon_{z} \\
J_{2}{ }^{\prime}=-\left(e_{1} e_{2}+e_{2} e_{3}+e_{1} e_{3}\right) \\
J_{3}{ }^{\prime}=e_{1} e_{2} e_{3}
\end{array}\right.
$$

$$
\left\{\begin{array}{l}
e_{1}=\frac{2}{3} \varepsilon_{x}-\frac{1}{3}\left(\varepsilon_{y}+\varepsilon_{z}\right) \\
e_{2}=\frac{2}{3} \varepsilon_{y}-\frac{1}{3}\left(\varepsilon_{x}+\varepsilon_{z}\right) \\
e_{3}=\frac{2}{3} \varepsilon_{z}-\frac{1}{3}\left(\varepsilon_{x}+\varepsilon_{y}\right)
\end{array}\right.
$$

where $\varepsilon_{x}, \varepsilon_{y}$ and $\varepsilon_{z}$ are strains in $\mathrm{X}, \mathrm{Y}$ and $\mathrm{Z}$ directions respectively.

If the maximum tensile strain of the element is lower than the ultimate tensile strain $\left(\varepsilon_{\max }<\varepsilon_{t u}\right.$ ), the unit will not undergo tensile failure. In this case, the energy damage failure criterion based on strain gradient is adopted as the criterion of element failure. Considering the influence of the strain gradient term, the formula for calculating the strain energy density of the element is proposed as follows:

$$
\frac{\mathrm{d} W}{\mathrm{~d} V}=\int_{0}^{\varepsilon_{i j}} \sigma_{i j} \mathrm{~d} \varepsilon_{i j}+\frac{1}{8} G l^{2}\left(4 \eta_{i j j} \eta_{i k k}+4 \eta_{i i k} \eta_{k j j}+4 \eta_{i i k} \eta_{j j k}+7 \eta_{i j k} \eta_{i j k}+2 \eta_{i j k} \eta_{k j i}\right)
$$




$$
\left\{\begin{array}{l}
(\mathrm{d} W / \mathrm{d} V)_{s}=\int_{0}^{\varepsilon_{s}} \sigma_{i j} \mathrm{~d} \varepsilon_{i j} \\
(\mathrm{~d} W / \mathrm{d} V)_{c}=\int_{0}^{\varepsilon_{o}} \sigma_{i j} \mathrm{~d} \varepsilon_{i j} \\
(\mathrm{~d} W / \mathrm{d} V)_{u}=\int_{0}^{\varepsilon_{u}} \sigma_{i j} \mathrm{~d} \varepsilon_{i j}
\end{array}\right.
$$

The energy damage failure criterion is determined by the change in strain energy density $(\mathrm{d} W / \mathrm{d} V)$. When $(\mathrm{d} W / \mathrm{d} V)<(\mathrm{d} W / \mathrm{d} V)_{s}=\int_{0}^{\varepsilon_{s}} \sigma_{i j} \mathrm{~d} \varepsilon_{i j} \quad\left(\varepsilon_{s}\right.$ is the yield strain in the process of loading), the material is in the linear elastic phase and no damage occurs inside the

311 element. When $(\mathrm{d} W / \mathrm{d} V) \geq(\mathrm{d} W / \mathrm{d} V)_{s}=\int_{0}^{\varepsilon_{s}} \sigma_{i j} \mathrm{~d} \varepsilon_{i j}$, the material enters into plastic damage, 312 indicated by the damage variable $\mathrm{d}$, and micro-cracks appear and begin to expand. When $313(\mathrm{~d} W / \mathrm{d} V) \geq(\mathrm{d} W / \mathrm{d} V)_{c}=\int_{0}^{\varepsilon_{o}} \sigma_{i j} \mathrm{~d} \varepsilon_{i j} \quad$ ( $\varepsilon_{o}$ is the residual strain in the process of loading), the 314 microcracks in the material develop into macroscopic cracks, and the rock mass enters the 315 residual stage, and there is still bearing capacity. When $(\mathrm{d} W / \mathrm{d} V) \geq(\mathrm{d} W / \mathrm{d} V)_{u}=\int_{0}^{\varepsilon_{u}} \sigma_{i j} \mathrm{~d} \varepsilon_{i j}$ 316 ( $\varepsilon_{u}$ is the ultimate strain in the process of loading), the unit is destroyed and can no longer 317 bear the load. As with the tensile failure, residual elastic modulus $E s$ is imparted to the failure 318 element to maintain the integrity and continuity of the overall calculation.

\section{5. Establishment of numerical analysis methods}

\subsection{Development of the simulation program}

We develop a program based on the finite element method to simulate splitting failure and zonal disintegration in the surrounding rock of cavern with high sidewall under high 
damage failure criterion which are established from the strain gradient theory and the continuous damage mechanics. In this section, we provide an introduction to the simulation program and compare the simulation results with those obtained from the geo-mechanical model test.

In numerical simulations based on elastic damage softening models, the effect of strain gradients must be taken into account. However, in general finite element analysis, the cell shape function has only first-order continuity and the second-order derivative of the displacement within the cell has a value of zero after interpolation. This cell analysis does not reflect the effects of strain gradients. Therefore, it is necessary to construct elements with higher order continuity, i.e. elements with $\mathrm{C}^{1}$-order continuity, and to require that the nodal displacements and their first-order derivatives maintain continuity. High-order hexahedral cells were constructed using Hermite interpolation functions, and the shape functions and stiffness matrices of the cells were derived (Zhang (2015)). This provides a technical basis for 337 considering strain gradient effects in numerical simulations. The simulation program was 338 developed using the finite element software ABAQUS as a platform.

In the elastic-plastic damage softening model, the total strain at any point is decomposes 340 into the Eulerian strain $\varepsilon_{i j}$ and the higher order strain $\eta_{i j k}$, which correspond to the Cauchy 341 stress $\sigma_{i j}$ and the higher order stress $\tau_{i j k}$, respectively. In general, the Cauchy stress $\sigma_{i j}$ and 342 Eulerian strain $\varepsilon_{i j}$ each have 6 independent components, while the higher order stress $\tau_{i j k}$ and 343 higher order strain $\eta_{i j k}$ each have 18 independent components, after taking symmetry into 344 account in the 3D condition.

345 The relationship between Cauchy stress and Eulerian strain is given by:

$$
\sigma=\mathbf{C} \varepsilon
$$



matrix $\boldsymbol{C}^{p d}=\left(1-D+\delta_{i j} D / 3\right) \boldsymbol{C}^{p}-\frac{2}{3} \frac{\Sigma}{E^{p}}$ given by:

where

$$
\begin{gathered}
\boldsymbol{\tau}=\left(\begin{array}{llllllllll}
\tau_{x x x} & \tau_{y y x} & \tau_{z z x} & \tau_{x y x} & \tau_{y z x} & \tau_{x z x} & \tau_{x x y} & \tau_{y y y} & \tau_{z z y} \\
& \tau_{x y y} & \tau_{y z y} & \tau_{x z y} & \tau_{x x z} & \tau_{y y z} & \tau_{z z z} & \tau_{x y z} & \tau_{y z z} & \tau_{x z z}
\end{array}\right)^{T}
\end{gathered}
$$

$$
\begin{aligned}
\boldsymbol{\eta}=\left(\begin{array}{llllllllll}
\eta_{x x x} & \eta_{y y x} & \eta_{z z x} & \eta_{x y x} & \eta_{y z x} & \eta_{x z x} & \eta_{x x y} & \eta_{y y y} & \eta_{z z y} \\
\eta_{x y y} & \eta_{y z y} & \eta_{x z y} & \eta_{x x z} & \eta_{y y z} & \eta_{z z z} & \eta_{x y z} & \eta_{y z z} & \eta_{x z z}
\end{array}\right)^{T}
\end{aligned}
$$

where $\boldsymbol{\Lambda}$ is an 18 x 18 matrix, $\boldsymbol{\Lambda}=l^{2}\left[\begin{array}{cc}D_{1} & D_{2} \\ D_{3} & D_{4}\end{array}\right]$. Wherein $D_{1}, D_{2}, D_{3}, D_{4}$ as follows:

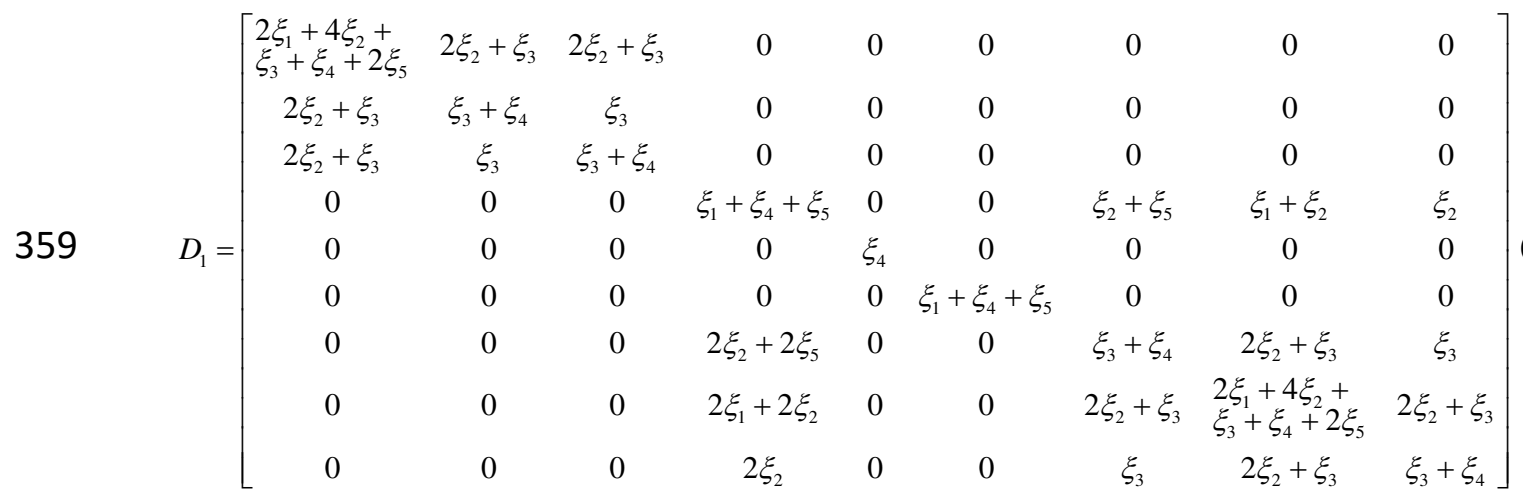


$360 \quad D_{2}=\left[\begin{array}{ccccccccc}2 \xi_{1}+2 \xi_{2} & 0 & 0 & 0 & 0 & 0 & 0 & 0 & 2 \xi_{1}+2 \xi_{2} \\ 2 \xi_{2}+2 \xi_{5} & 0 & 0 & 0 & 0 & 0 & 0 & 0 & 2 \xi_{2} \\ 2 \xi_{2} & 0 & 0 & 0 & 0 & 0 & 0 & 0 & 2 \xi_{2}+2 \xi_{5} \\ 0 & 0 & \xi_{5} & 0 & 0 & 0 & \xi_{5} & 0 & 0 \\ 0 & 0 & 0 & \xi_{3} & 0 & 2 \xi_{2} & 0 & 0 & 0 \\ 0 & \xi_{1} & 0 & \xi_{2}+\xi_{5} & \xi_{2} & \xi_{1}+\xi_{2} & 0 & 0 & 0 \\ 0 & 0 & 0 & 0 & 0 & 0 & 0 & 2 \xi_{2} & 0 \\ 0 & 0 & 0 & 0 & 0 & 0 & 0 & 2 \xi_{1}+2 \xi_{2} & 0 \\ 0 & 0 & 0 & 0 & 0 & 0 & 0 & 2 \xi_{2}+2 \xi_{5} & 0\end{array}\right]$

$361 \quad D_{3}=\left[\begin{array}{ccccccccc}\xi_{1}+\xi_{2} & \xi_{2}+\xi_{5} & \xi_{2} & 0 & 0 & 0 & 0 & 0 & 0 \\ 0 & 0 & 0 & 0 & 0 & \xi_{1} & 0 & 0 & 0 \\ 0 & 0 & 0 & 0 & \xi_{5} & 0 & 0 & 0 & 0 \\ 0 & 0 & 0 & 0 & 0 & 2 \xi_{2}+2 \xi_{5} & 0 & 0 & 0 \\ 0 & 0 & 0 & 0 & 0 & 2 \xi_{2} & 0 & 0 & 0 \\ 0 & 0 & 0 & 0 & 0 & 2 \xi_{1}+2 \xi_{2} & 0 & 0 & 0 \\ 0 & 0 & 0 & 0 & \xi_{5} & 0 & 0 & 0 & 0 \\ 0 & 0 & 0 & \xi_{1} & 0 & 0 & \xi_{2} & \xi_{1}+\xi_{2} & \xi_{2}+\xi_{5} \\ \xi_{1}+\xi_{2} & \xi_{2} & \xi_{2}+\xi_{5} & 0 & 0 & 0 & 0 & 0 & 0\end{array}\right]$

$$
D_{4}=\left[\begin{array}{ccccccccc}
\xi_{1}+\xi_{4}+\xi_{5} & 0 & 0 & 0 & 0 & 0 & 0 & 0 & \xi_{1} \\
0 & \xi_{1}+\xi_{4}+\xi_{5} & 0 & \xi_{2} & \xi_{2}+\xi_{5} & \xi_{1}+\xi_{2} & 0 & 0 & 0 \\
0 & 0 & \xi_{4} & 0 & 0 & 0 & \xi_{5} & 0 & 0 \\
0 & 2 \xi_{2} & 0 & \xi_{3}+\xi_{4} & \xi_{3} & 2 \xi_{2}+\xi_{3} & 0 & 0 & 0 \\
0 & 2 \xi_{2}+\xi_{5} & 0 & \xi_{3} & \xi_{3}+\xi_{4} & 2 \xi_{2}+\xi_{3} & 0 & 0 & 0 \\
0 & 2 \xi_{1}+2 \xi_{2} & 0 & 2 \xi_{2}+\xi_{3} & 2 \xi_{2}+\xi_{3} & 2 \xi_{1}+4 \xi_{2}+ & 0 & 0 & 0 \\
0 & 0 & \xi_{5} & 0 & 0 & 0 & \xi_{4}+2 \xi_{5} & 0 & 0 \\
0 & 0 & 0 & 0 & 0 & 0 & 0 & \xi_{1}+\xi_{4}+\xi_{5} & 0 \\
\xi_{1} & 0 & 0 & 0 & 0 & 0 & 0 & 0 & \xi_{1}+\xi_{4}+\xi_{5}
\end{array}\right]
$$
are $\xi_{1}=\frac{1}{2} G, \xi_{2}=\frac{1}{4} G, \xi_{3}=G, \xi_{4}=\frac{7}{4} G, \xi_{5}=\frac{1}{4} G$. can be obtained from Eq. (20) as:

$$
\boldsymbol{\tau}=\frac{1-D}{2(1+v)} \boldsymbol{\Lambda} \boldsymbol{\eta}-\frac{\Sigma}{E^{p}} l^{2} \boldsymbol{\varepsilon}^{p}
$$

Fig. 10 shows the simulation program flow chart. 

discussed in Section 2. As shown in Fig. 11, the numerical model has a scale of $210 \mathrm{~m}$ along

$374 \mathrm{X}, \mathrm{Y}$ and $\mathrm{Z}$. The 3D computational grid consists of 60000 elements and 67769 nodes. The 375 external loads applied on the numerical model are shown in Fig. 11. According to the 376 laboratory experiments (Zhang et al., 2021), the initial elastic modulus is $E=41.50 \mathrm{GPa}$, the 377 Poisson's ratio is $v=0.27$, the density rock is $\rho=26.60 \mathrm{KNgm}^{-3}$, the compressive strength is $378 \sigma_{c}=128.80 \mathrm{MPa}$, the tensile strength is $\sigma_{t}=8.00 \mathrm{MPa}$, the Lame constant is $G=16.34 \mathrm{GPa}$, 379 the internal length parameter of the material is $l=0.01 \mathrm{~m}$. The boundary conditions and cavern construction process in the numerical model are consistent with the physical model.

\subsection{Simulation results}

The above external loads were applied to the numerical model shown in Fig. 11. After the calculations are balanced, the displacements and strains at each node in the model are set to zero, thus establishing the initial ground stress field of the model. The cavern was excavated to obtain the displacement, strain and stress fields of the cavern envelope. The calculated results were transformed into a column coordinate system to obtain the distribution of radial displacement, radial strain and radial stress of the surrounding rock. (Fig. 12).

As shown in Fig. 12, spaced fracture zones occur in the surrounding rock. The fracture zones are distributed on both sides of the cavern and parallel to the cavern sidewalls. Three rupture zones appear around the cavern chamber in terms of displacement, strain and stress.

391 Near the rupture zones, deformation is concentrated in the middle of the cavern sidewalls and stresses are parallel to the height of the cavern sidewalls. This is consistent with Fig. 5, which shows a vertical fracture parallel to the wall in the vicinity of the cavern. However, the 
simulations. This may be due to the fact that the intrinsic model used in the numerical

calculations does not take into account the damage effect of excavation on the surrounding rock.

In order to facilitate the comparative analysis between the numerical simulation results and the model test results, the radial displacement data of the numerical model at the corresponding locations of the test model monitoring points were read out, as shown in Table

401 3. A comparison of the model test and radial displacement numerical simulation results is shown in Fig. 13 for line A as an example. From the numerical model, it can be seen that the radial displacement of the surrounding rock shows an oscillatory pattern, which is characterised by alternating peaks and troughs, with the amplitude of the oscillations decreasing with distance from the wall. These characteristics are consistent with the radial displacement variation pattern measured by the model test. The reliability of the elastic damage softening model and numerical analysis method based on the ABAQUS platform is verified.

The results of the numerical simulation show that the excavation unloading leads to the rupture of the surrounding rock. The stress waves generated by the rock rupture propagate outwards from the cavern walls and form a new stress field in the cavern envelope. The rock, after superimposed with the original rock stress field, may rupture again, forming new rupture and non-ruptured zones.

\section{Conclusions}

Splitting failure in deeply buried high sidewall cavern is a specific and regular strain

416 localisation phenomenon. The study of splitting failure should start with the strain localisation

417 and strain softening of the rock behind the peak. The effect of strain gradients should also be 418 considered. 
420 damage softening model for splitting failure was developed. The relationship between rock 421 damage and energy dissipation was analysed. Based on the strain energy density theory, a 422 strain gradient-based splitting failure criterion was established. To account for strain gradient effects, an eight-node high-order hexahedral cell was

424 constructed. The shape functions and stiffness matrices of the higher order cells are derived. A 425 numerical analysis method for splitting failure is proposed. A splitting failure calculation program based on ABAQUS is also developed. The numerical simulation results based on

427 ABAQUS and 3D geomechanical model tests are in general agreement. The reliability of the 428 splitting failure elastic-plastic damage softening model and the numerical analysis method of 429 splitting failure were effectively verified.

430

\section{Acknowledgement}

432 This study was financially supported by the Natural Science Foundation of China 433 (NO:41772282) and the Taishan Scholars Project Foundation of Shandong Province and the 434 National Key Research Development Project of China (No. 2016YFC0401804).

435 Conflicts of Interest: The authors declare that they have no conflict of interest. 


\section{Reference}

438 Bauch, E., \& Lempp, C., 2004. Rock splitting in the surrounds of underground openings: an 439 experimental approach using triaxial extension tests. In Engineering geology for infrastructure planning 440 in Europe (pp. 244-254). Springer, Berlin, Heidelberg.

441 Chen, X. G., Wang, Y., Zhang, Q. Y., Li, S. C., \& Nordlund, E. (2013a). Analogical model test and theoretical analysis on zonal disintegration based on filed monitoring in deep tunnel. European Journal of Environmental and Civil Engineering, 17(sup1), s33-s52.

444 Chen, X. G., Zhang, Q. Y., Wang, Y., Li, S. C., \& Wang, H. P. (2013b). In situ observation and model test on zonal disintegration in deep tunnels. Journal of Testing and Evaluation, 41(6), 990-1000.

Chen, X. G., Zhang, Q. Y., Wang, Y., Liu, D. J., \& Zhang, N. (2013c). Model test of anchoring effect on zonal disintegration in deep surrounding rock masses. The Scientific World Journal, 2013.

Dyskin, A. V., Sahouryeh, E., Jewell, R. J., Joer, H., \& Ustinov, K. B., 2003. Influence of shape and locations of initial 3-D cracks on their growth in uniaxial compression. Engineering Fracture Mechanics, 70(15), 2115-2136.

Eshel, N. N., \& Rosenfeld, G. (1975). Axi-symmetric problems in elastic materials of grade two. Journal of the Franklin Institute, 299(1), 43-51.

453 Fang, Z., \& Harrison, J. P., 2002. Development of a local degradation approach to the modelling of 454 brittle fracture in heterogeneous rocks. International Journal of Rock Mechanics and Mining Sciences, $45539(4), 443-457$.

456 Fleck, N.A., Hutchinson, J.W., 2001. A reformulation of strain gradient plasticity. J. Mech. Phys. Solids 49, 2245-2271.

Gao, Q., Zhang, Q., \& Xiang, W. (2019). Mechanism of Zonal Disintegration Phenomenon (ZDP) Around Deep Roadway Under Dynamic Excavation. Geotechnical and Geological Engineering, 37(1), $25-41$.

461 Gao, Q., Zhang, Q., Zhang, X., \& Zhang, L. (2018). Geomechanical Model Test and Energy 462 Mechanism Analysis of Zonal Disintegration in Deep Surrounding Rock. Geosciences, 8(7), 237. 
463 Gong, F. Q., Luo, Y., Li, X. B., Si, X. F., \& Tao, M., 2018. Experimental simulation investigation on 464 rockburst induced by spalling failure in deep circular tunnels. Tunnelling and Underground Space 465 Technology, 81, 413-427.

466 Gong, Q. M., Yin, L. J., Wu, S. Y., Zhao, J., \& Ting, Y., 2012. Rock burst and slabbing failure and its 467 influence on TBM excavation at headrace tunnels in Jinping II hydropower station. Engineering 468 Geology, 124, 98-108.

469 Gudmundson, P. (2004). A unified treatment of strain gradient plasticity. Journal of the Mechanics and 470 Physics of Solids, 52(6), 1379-1406.

471 Gurtin, M.E., 2000. On the plasticity of single crystals: free energy, microforces, plastic-strain 472 gradients.J. Mech. Phys. Solids 48, 989-1036.

473 Gurtin, M.E., 2002. A gradient theory of single-crystal viscoplasticity that accounts for geometrically

474 necessary dislocations. J. Mech. Phys. Solids 50, 5-32.

475 Gurtin, M.E., 2003. On a framework for small-deformation viscoplasticity: free energy, microforces, 476 strain gradients. Int. J. Plast. 19, 47-90.

477 Gurtin, M. E., \& Anand, L. (2005). A theory of strain-gradient plasticity for isotropic, plastically 478 irrotational materials. Part I: Small deformations. Journal of the Mechanics and Physics of Solids, 53(7), 479 1624-1649.

480 Hibino, S., 2001. Rock mass behavior of large-scale cavern during excavation and trend of 481 underground space use. JOURNAL-MINING AND MATERIALS PROCESSING INSTITUTE OF 482 JAPAN, 117(3), 167-176.

483 Jia, P., Yang, T. H., \& Yu, Q. L. (2012). Mechanism of parallel fractures around deep underground 484 excavations. Theoretical and Applied Fracture Mechanics, 61, 57-65.

485 Jiang, Q., Feng, X. T., Fan, Y., Fan, Q., Liu, G., Pei, S., \& Duan, S., 2017. In situ experimental 486 investigation of basalt spalling in a large underground powerhouse cavern. Tunnelling and 487 Underground Space Technology, 68, 82-94.

488 Lam, D. C., Yang, F., Chong, A. C. M., Wang, J., \& Tong, P. (2003). Experiments and theory in strain 489 gradient elasticity. Journal of the Mechanics and Physics of Solids, 51(8), 1477-1508.

490 Li, D., Li, C. C., \& Li, X., 2011. Influence of sample height-to-width ratios on failure mode for 
rectangular prism samples of hard rock loaded in uniaxial compression. Rock Mechanics and Rock Engineering, 44(3), 253-267.

Li, S. C., \& Feng, X. D. (2013). Numerical model for the zonal disintegration of the rock mass around deep underground workings. Theoretical and Applied Fracture Mechanics, 67, 65-73.

Liu, G., Feng, X. T., Jiang, Q., Yao, Z., \& Li, S., 2017. In situ observation of spalling process of intact rock mass at large cavern excavation. Engineering geology, 226, 52-69.

Liu, H. Y., Kou, S. Q., \& Lindqvist, P. A., 2002. Numerical simulation of the fracture process in cutting heterogeneous brittle material. International journal for numerical and analytical methods in geomechanics, 26(13), 1253-1278.

Liu, Z. Q., \& Yu, D. M. (2012). Elastoplastic analytical solutions for displacements of deep-buried circular tunnels considering intermediate principal stress. Journal of Henan Polytechnic University(Natural Science), 31(4), 469-473.

Martin, C. D., \& Maybee, W. G., 2000. The strength of hard-rock pillars. International Journal of Rock Mechanics and Mining Sciences, 37(8), 1239-1246.

Mentzel, A., Steinmann, P., 2000. On the continuum formulation of higher order gradient plasticity for single and polycrystals. J. Mech. Phys. Solids 48, 1777-1796.

Mindlin, R. D. (1965). Second gradient of strain and surface-tension in linear elasticity. International Journal of Solids and Structures, 1(4), 417-438.

Ortlepp, W. D., \& Stacey, T. R., 1994. Rockburst mechanisms in tunnels and shafts. Tunnelling and Underground Space Technology, 9(1), 59-65.

Ortlepp, W. D., 1997. Rock fracture and rockbursts: an illustrative study. South African Institute of Mining and Metallurgy.

Sahouryeh, E., Dyskin, A. V., \& Germanovich, L. N., 2002. Crack growth under biaxial compression. Engineering Fracture Mechanics, 69(18), 2187-2198.

Sharif, L. K., Elmo, D., \& Stead, D., 2019. Improving DFN-geomechanical model integration using a novel automated approach. Computers and Geotechnics, 105, 228-248.

Steinmann, P. (1994). A micropolar theory of finite deformation and finite rotation multiplicative elastoplasticity. International Journal of Solids and Structures, 31(8), 1063-1084. 

materials containing three flaws-part II: numerical approach. International Journal of Rock Mechanics and Mining Sciences, 38(7), 925-939. zones around underground cavity faces. Computers and Geotechnics, 54, 33-45.

524 Wang, Z., Li, Y., Zhu, W., Xue, Y., \& Yu, S., 2016. Splitting failure in side walls of a large-scale 525 underground cavern group: a numerical modelling and a field study. Springerplus, 5(1), 1528.

526 Wong, R. H. C., Law, C. M., Chau, K. T., \& Zhu, W. S., 2004. Crack propagation from 3-D surface 527 fractures in PMMA and marble specimens under uniaxial compression. International Journal of Rock 528 Mechanics and Mining Sciences.

529 Wowk, D., Alousis, L., \& Underhill, P. R., 2019. An adaptive remeshing technique for predicting the growth of irregular crack fronts using p-version finite element analysis. Engineering Fracture Mechanics, 207, 36-47.

532 Yang, F. A. C. M., Chong, A. C. M., Lam, D. C. C., \& Tong, P. (2002). Couple stress based strain 533 gradient theory for elasticity. International Journal of Solids and Structures, 39(10), 2731-2743.

534 Yoshida, T., Ohnishi, Y., Nishiyama, S., Hirakawa, Y., \& Mori, S., 2004. Behavior of discontinuties 535 during excavation of two large underground caverns. International Journal of Rock Mechanics and 536 Mining Sciences, 41(SUPPL. 1).

537 Zbib, H. M., \& Aifantis, E. C. (1988a). A gradient-dependent model for the Portevin-Le Chatelier effect. 538 Scripta metallurgica, 22(8), 1331-1336.

539 Zbib, H. M., \& Aifantis, E. C. (1988b). On the structure and width of shear bands. Scripta metallurgica, 540 22(5), 703-708.

541 Zhao, J., Sheng, D., \& Sloan, S. W. (2007). Cavity expansion of a gradient-dependent solid cylinder. 542 International journal of solids and structures, 44(13), 4342-4368.

543 Zhang X T. (2015). The research on failure mechanism and numerical simulate on analysis of zonal 544 disintegration in deep tunnel. (Doctoral dissertation, Shandong University). [in Chinese]

545 Zhang, Q., Liu, C., Duan, K., Zhang, Z., \& Xiang, W. (2019a). True Three-Dimensional 546 Geomechanical Model Tests for Stability Analysis of Surrounding Rock During the Excavation of a 547 Deep Underground Laboratory. Rock Mechanics and Rock Engineering, 1-21. 
548 Zhang, Q. Y., Ren, M. Y., Duan, K., Wang, W. S., Gao, Q., Lin, H. X., ... \& Jiao, Y. Y. (2019b). 549 Geo-mechanical model test on the collaborative bearing effect of rock-support system for deep tunnel 550 in complicated rock strata. Tunnelling and Underground Space Technology, 91, 103001.

551 Zhang, Q. Y., Zhang, Y., Duan, K., Liu, C. C., Miao, Y. S., \& Wu, D. (2019c). Large-scale 552 geo-mechanical model tests for the stability assessment of deep underground complex under 553 true-triaxial stress. Tunnelling and Underground Space Technology, 83, 577-591.

554 Zhang, Q., Zhang, X., Wang, Z., Xiang, W., \& Xue, J. (2017). Failure mechanism and numerical 555 simulation of zonal disintegration around a deep tunnel under high stress. International Journal of Rock 556 Mechanics and Mining Sciences, 93, 344-355.

557 Zhang, Q. Y., Zhang, X. T., Xiang, W., Chen, X., Cao, G., \& Xu, X. (2013). Model test study of zonal 558 disintegration in deep rock mass under different cavern shapes and loading conditions. Chinese Journal 559 of Rock Mechanics and Engineering, 32(8), 1564-1571.

560 Zhu, W. S., Li, X. J., Zhang, Q. B., Zheng, W. H., Xin, X. L., Sun, A. H., \& Li, S. C., 2010. A study on 561 sidewall displacement prediction and stability evaluations for large underground power station caverns. 562 International Journal of Rock Mechanics and Mining Sciences, 47(7), 1055-1062. 
565

566 List of Tables

567 Table. 1 The physical and mechanical properties of the prototype and the analogous material.

568 Table. 2 Components ratio of IBSCM.

569 Table. 3 The radial displacement of model test and numerical simulation.

570 


\section{$572 \quad$ List of Figures}

573 Fig 1. Geo-mechanical model test loading scheme. $(\sigma 1=27.30 \mathrm{MPa}, \sigma 2=16.16 \mathrm{MPa}$ and

$574 \sigma 3=15.25 \mathrm{MPa})$

575 Fig 2. Layout of monitoring sections (a) and monitoring sensors (b) (Unit: mm). Section I: the 576 radial stress monitoring section; Section II: the radial deformation monitoring section; Section III:

577 the tangential stress monitoring section.

578 Fig 3. True 3D loading system. (a) Hydraulic 3D loading system; (b) Overview of the 579 geo-mechanical model test system. 1 - Intelligent hydraulic 3D loading system; 2 - Cavern 580 excavation window; 3 - Counter-force frame system; 4 - Displacement acquisition system.

581 Fig 4. Schematic diagram showing the excavation procedure in the main powerhouse.

582 Fig 5. Fracture patterns around the cavern with high sidewall.

583 Fig 6. Variation of the radial displacement around the cavern.

584 Fig 7. Variation of the radial stress around the cavern.

585 Fig 8. Variation of the tangential stress around the cavern.

586 Fig 9. Stress-strain curve of uniaxial compression. (Gao et al., 2019)

587 Fig 10. The flow chart of zonal disintegration calculation program.

588 Fig 11. Numerical model generated for the simulation of high sidewall cavern.

589 Fig 12. Simulation results in terms of the contour of: (a) Radial displacement; (b) Radial 590 stress; and (c) Tangential stress in the surrounding rock of the cavern.

591 Fig 13. Comparison of the radial displacement of the cavern obtained from the geomechanical 592 model test and the numerical simulation. 
Figures

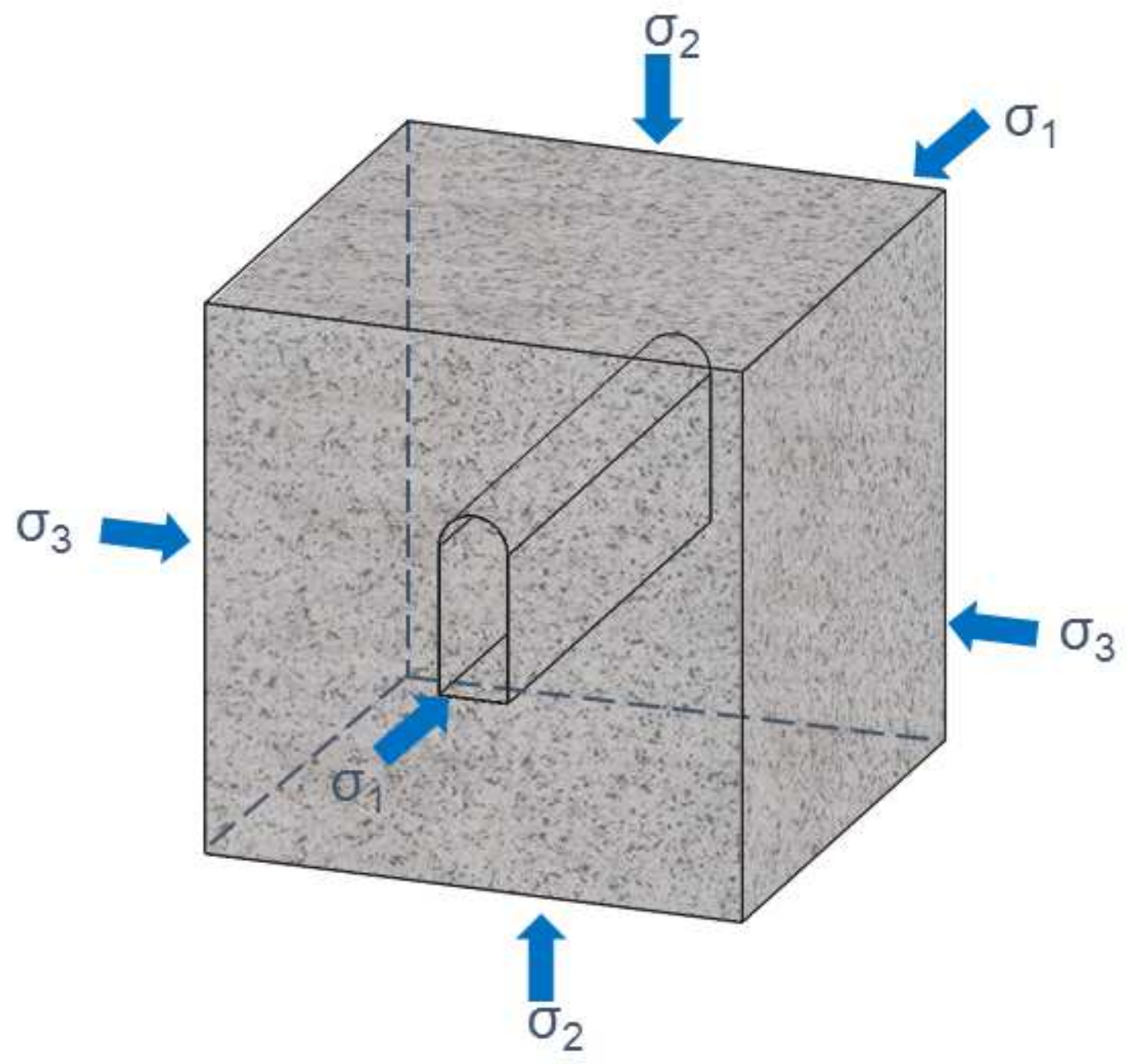

Figure 1

Geo-mechanical model test loading scheme. ( $\sigma 1=27.30 \mathrm{MPa}, \sigma 2=16.16 \mathrm{MPa}$ and $\sigma 3=15.25 \mathrm{MPa})$ 

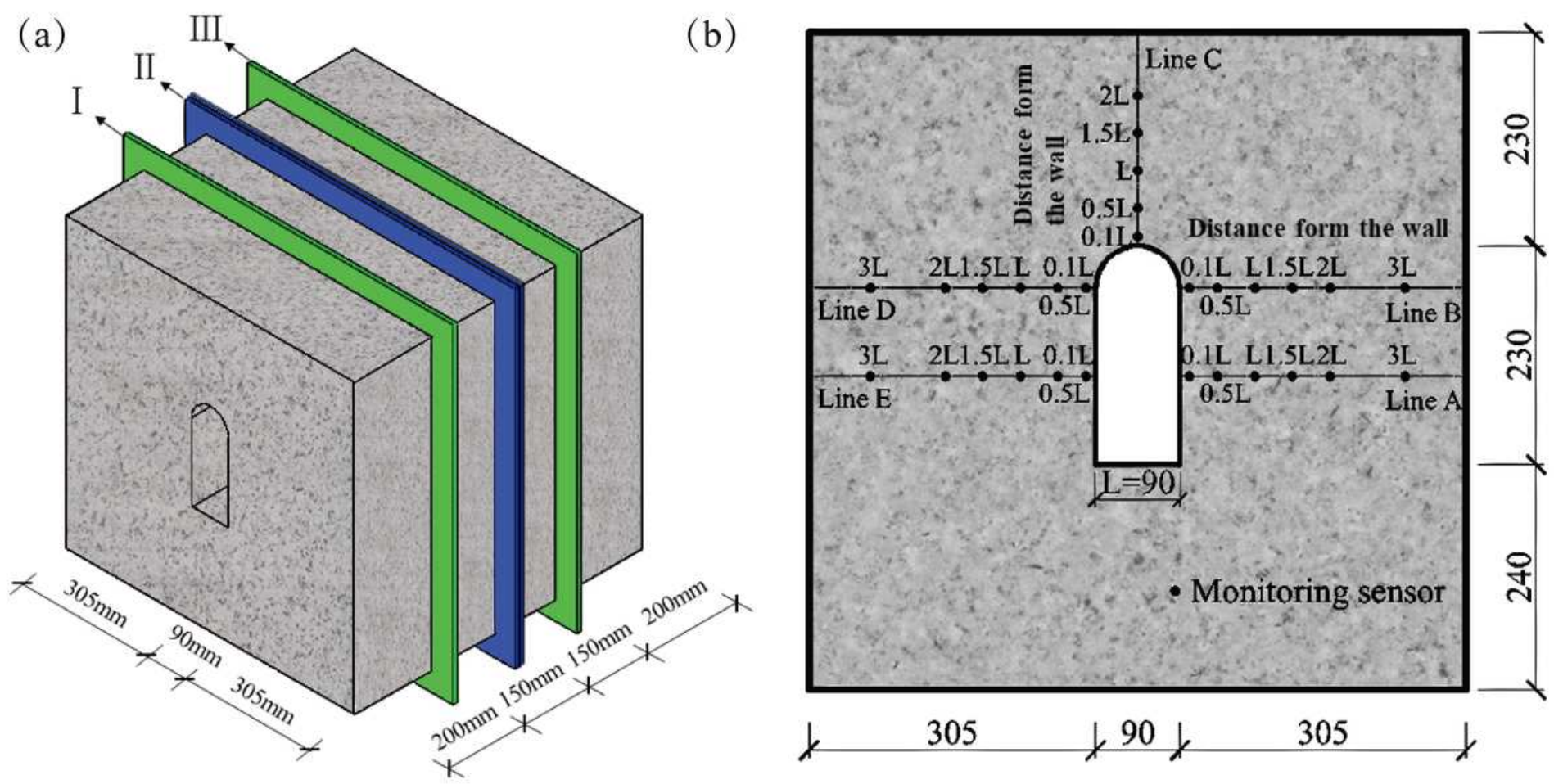

\section{Figure 2}

Layout of monitoring sections (a) and monitoring sensors (b) (Unit: $\mathrm{mm}$ ). Section I: the radial stress monitoring section; Section II: the radial deformation monitoring section; Section III: the tangential stress monitoring section.

(a)
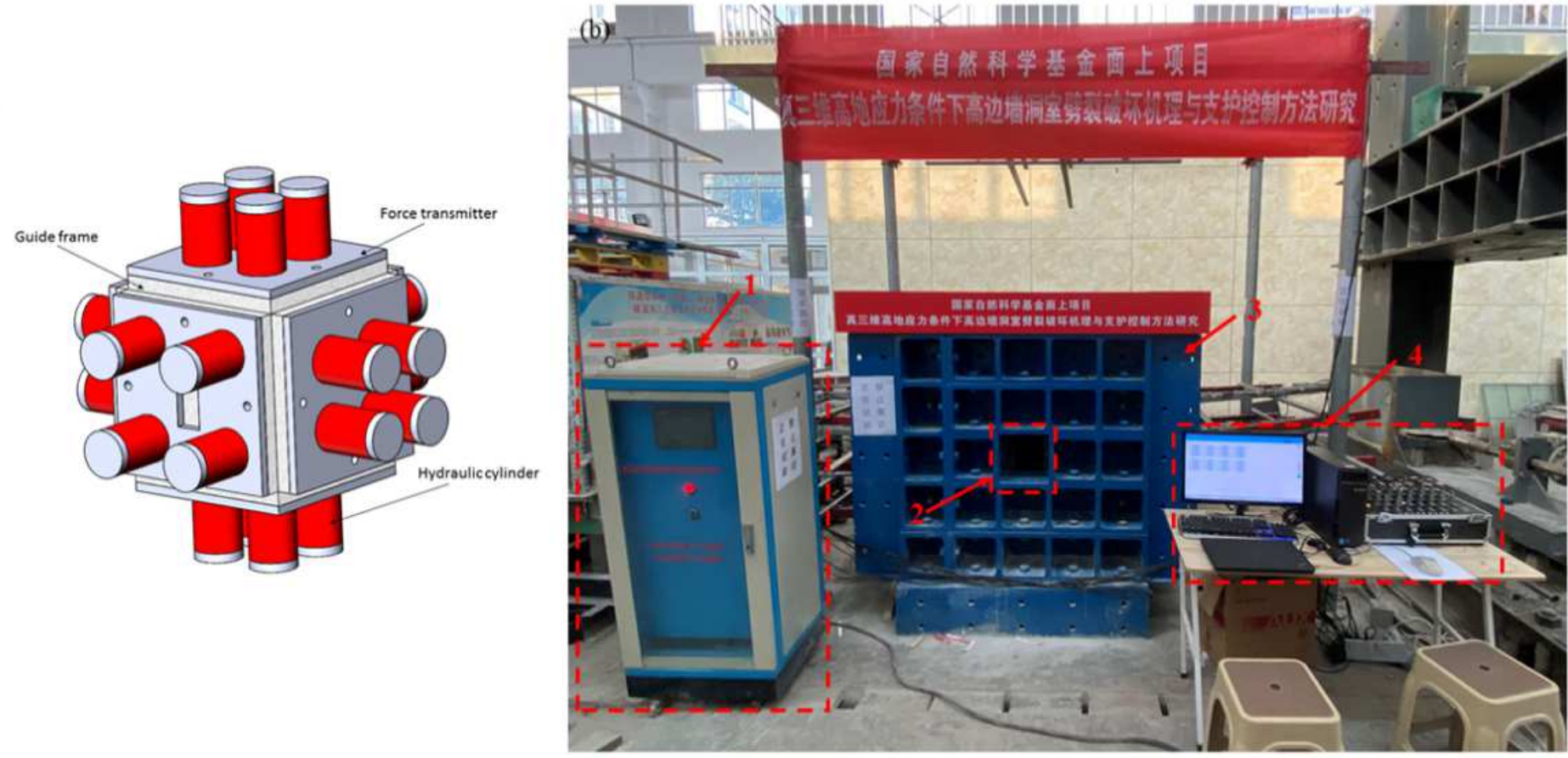
True 3D loading system. (a) Hydraulic 3D loading system; (b) Overview of the geo-mechanical model test system. 1 - Intelligent hydraulic 3D loading system; 2 - Cavern excavation window; 3 - Counter-force frame system; 4 - Displacement acquisition system.

\section{Figure 4}

Schematic diagram showing the excavation procedure in the main powerhouse.

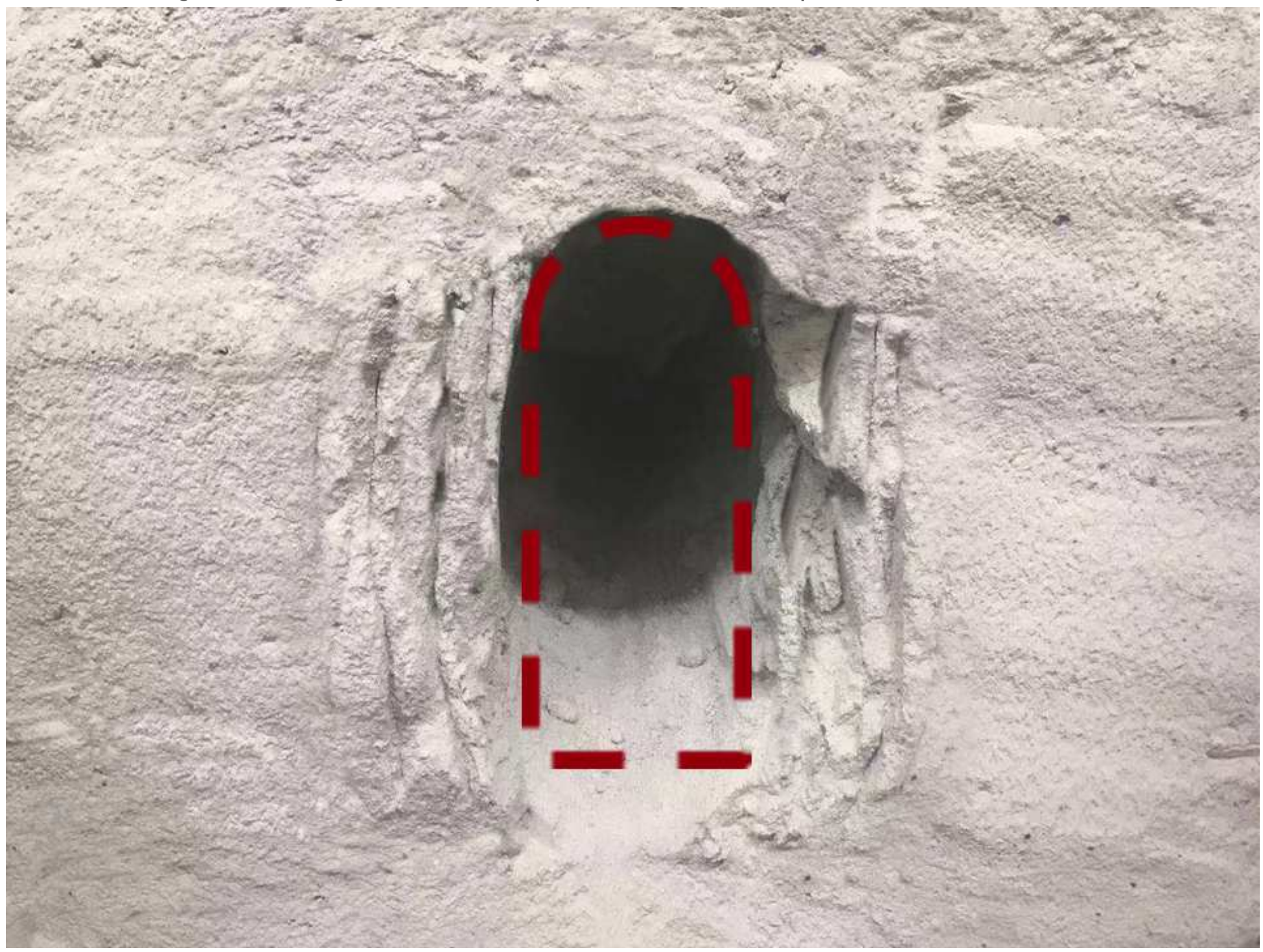

\section{Figure 5}

Fracture patterns around the cavern with high sidewall. 


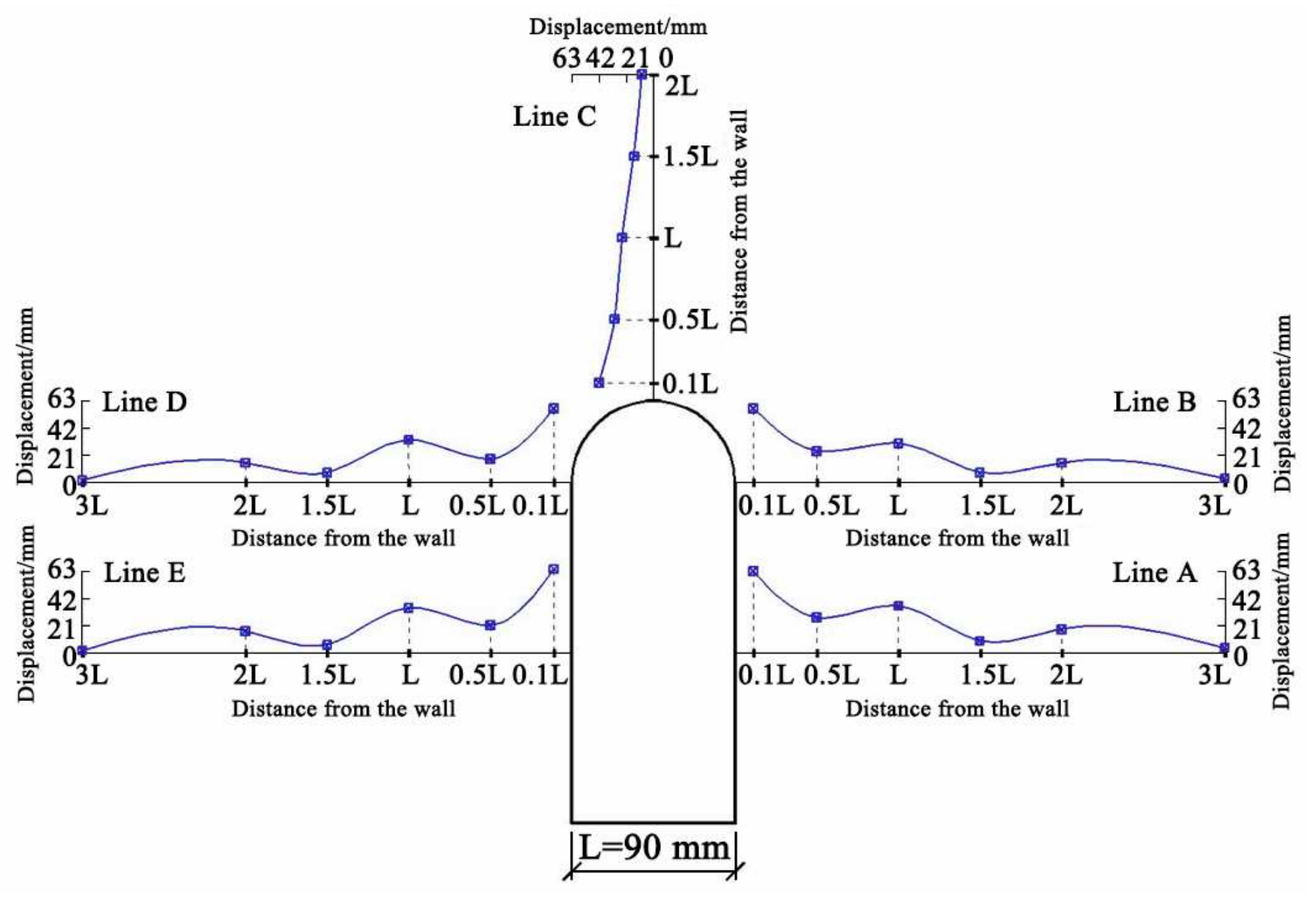

Figure 6

Variation of the radial displacement around the cavern. 


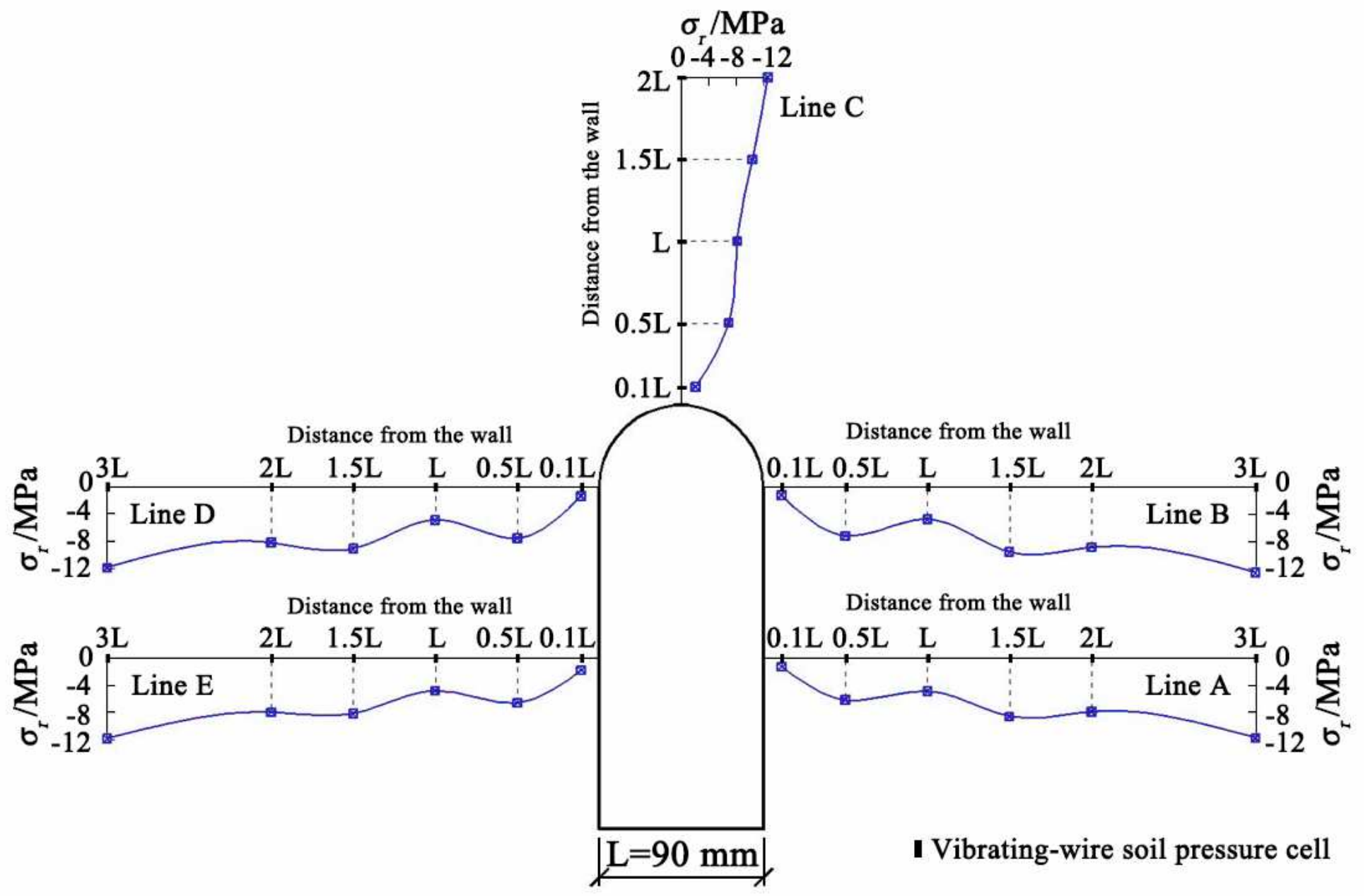

Figure 7

Variation of the radial stress around the cavern. 


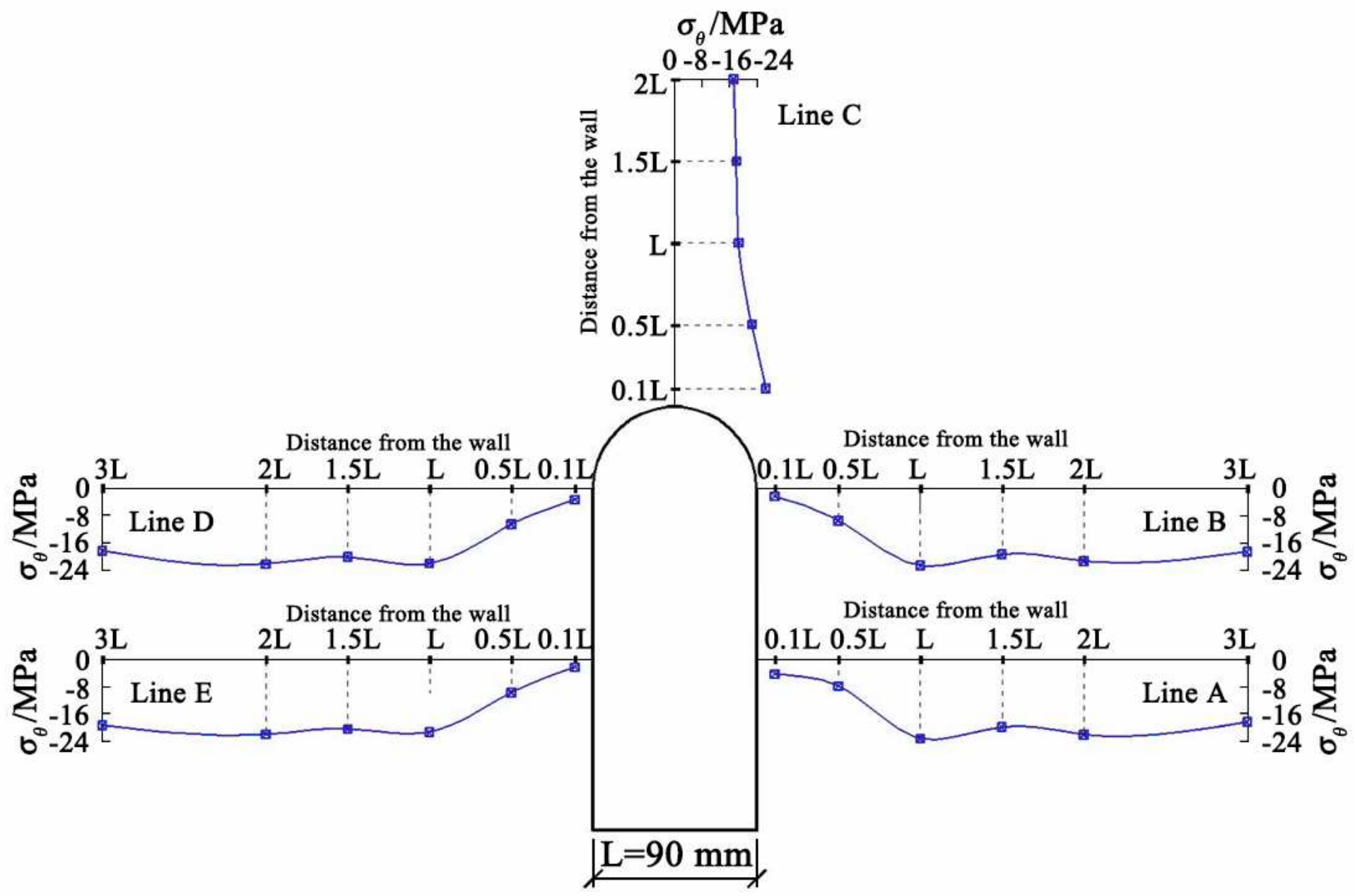

Figure 8

Variation of the tangential stress around the cavern. 


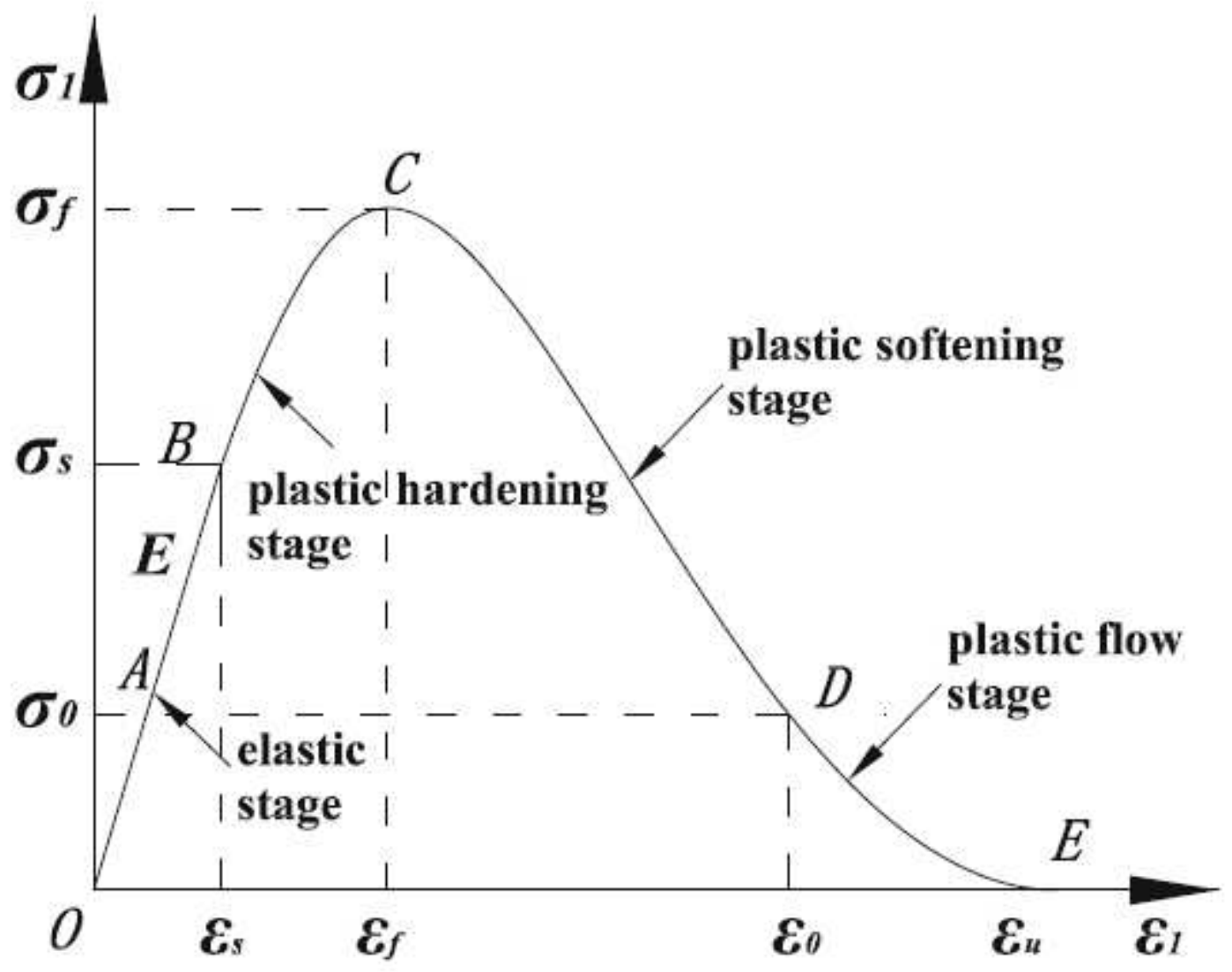

Figure 9

Stress-strain curve of uniaxial compression. (Gao et al., 2019) 


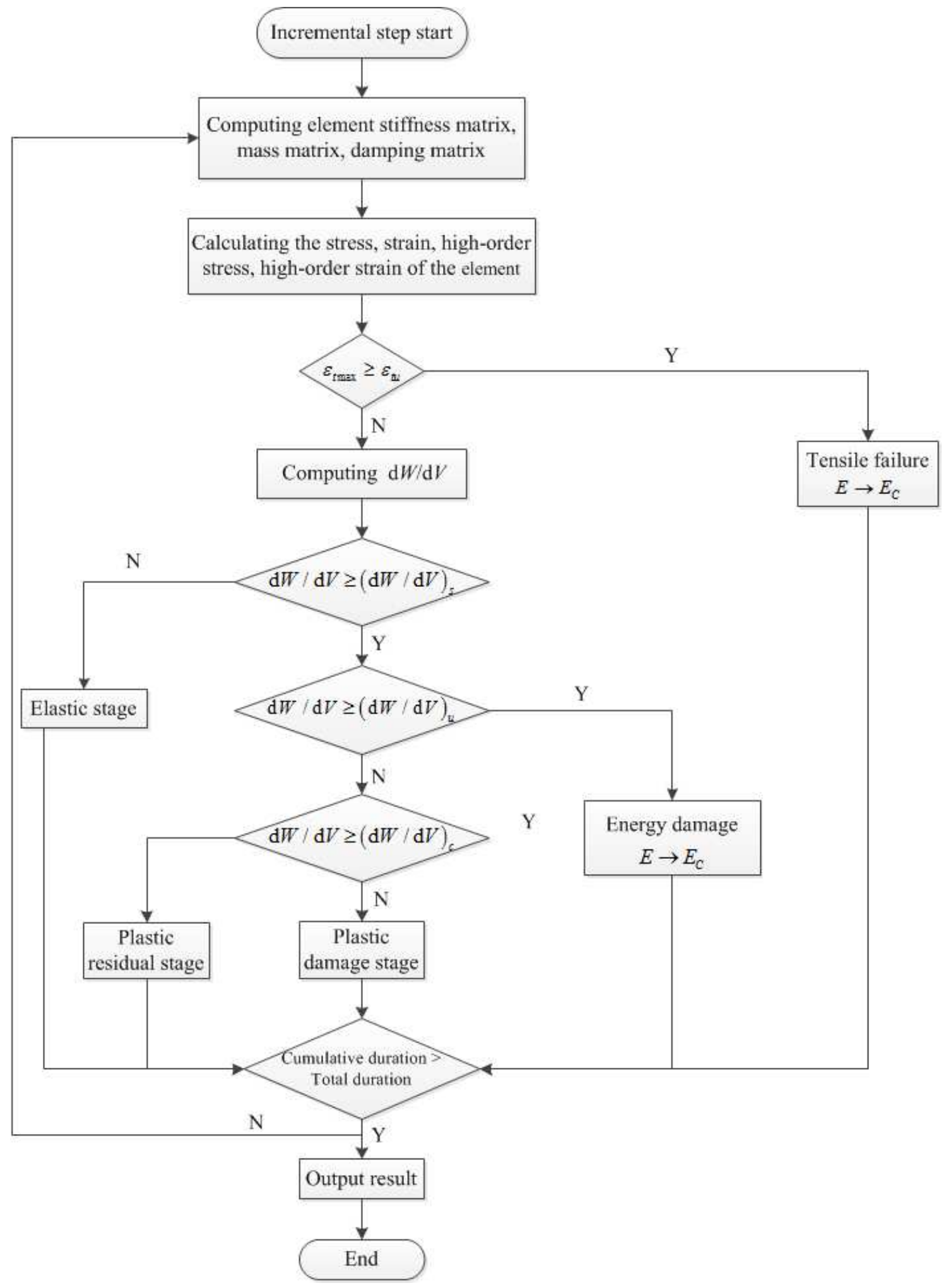

\section{Figure 10}

The flow chart of zonal disintegration calculation program. 


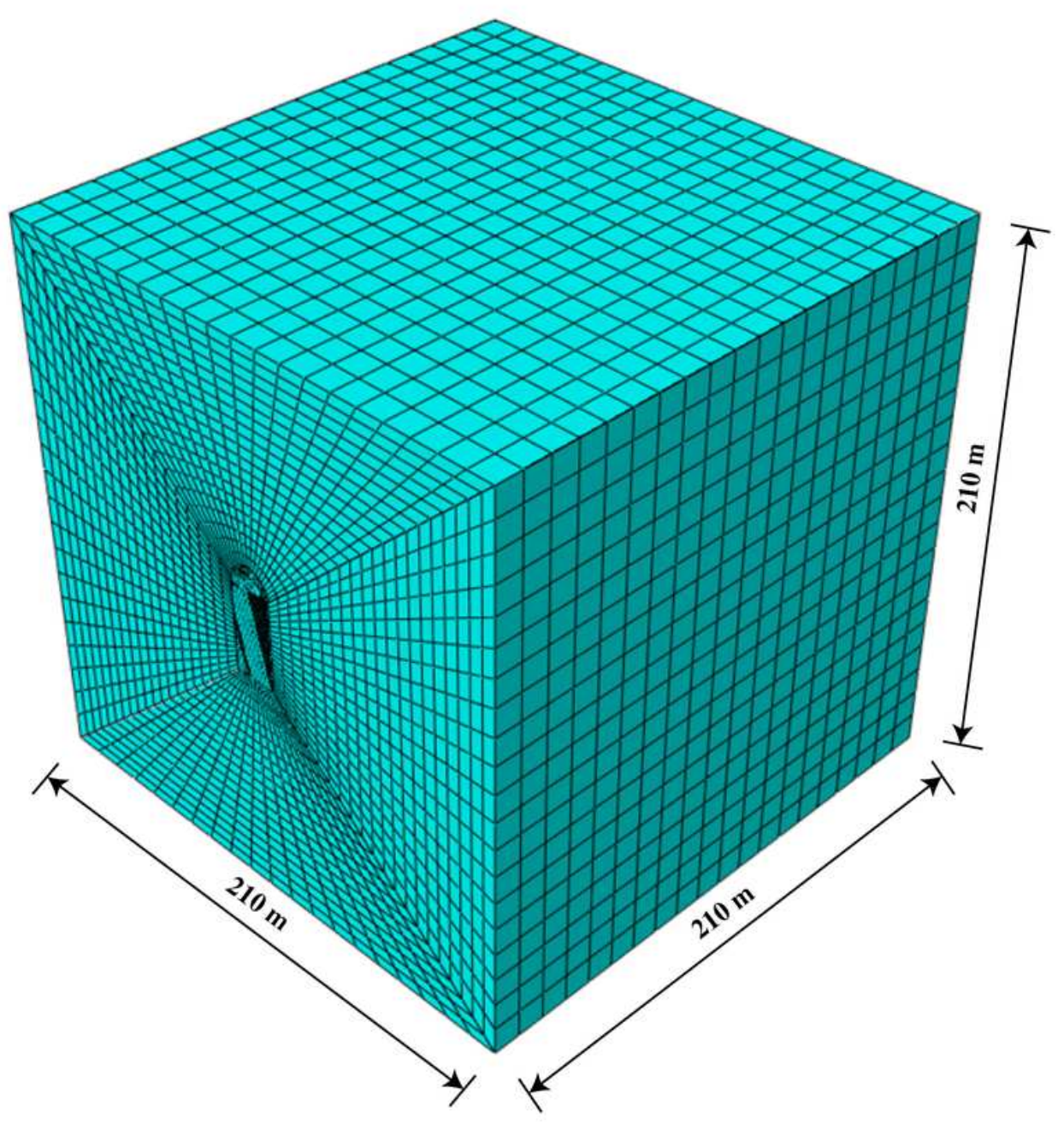

Figure 11

Numerical model generated for the simulation of high sidewall cavern. 
(a)

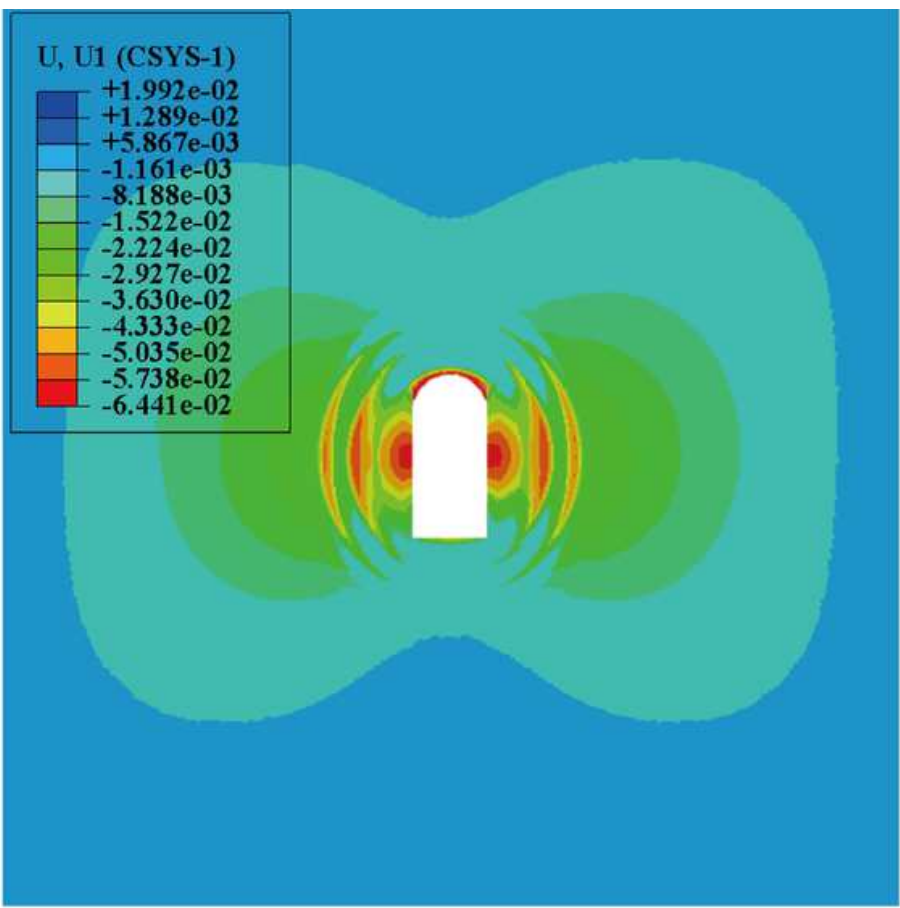

(b)

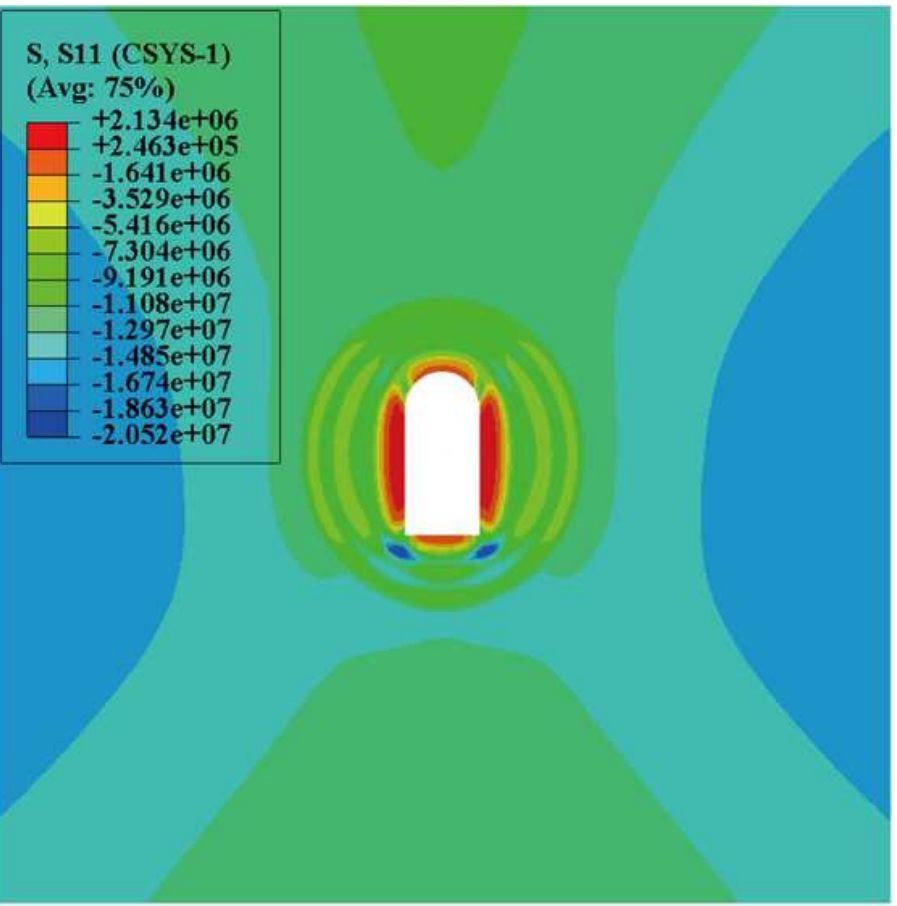

(c)

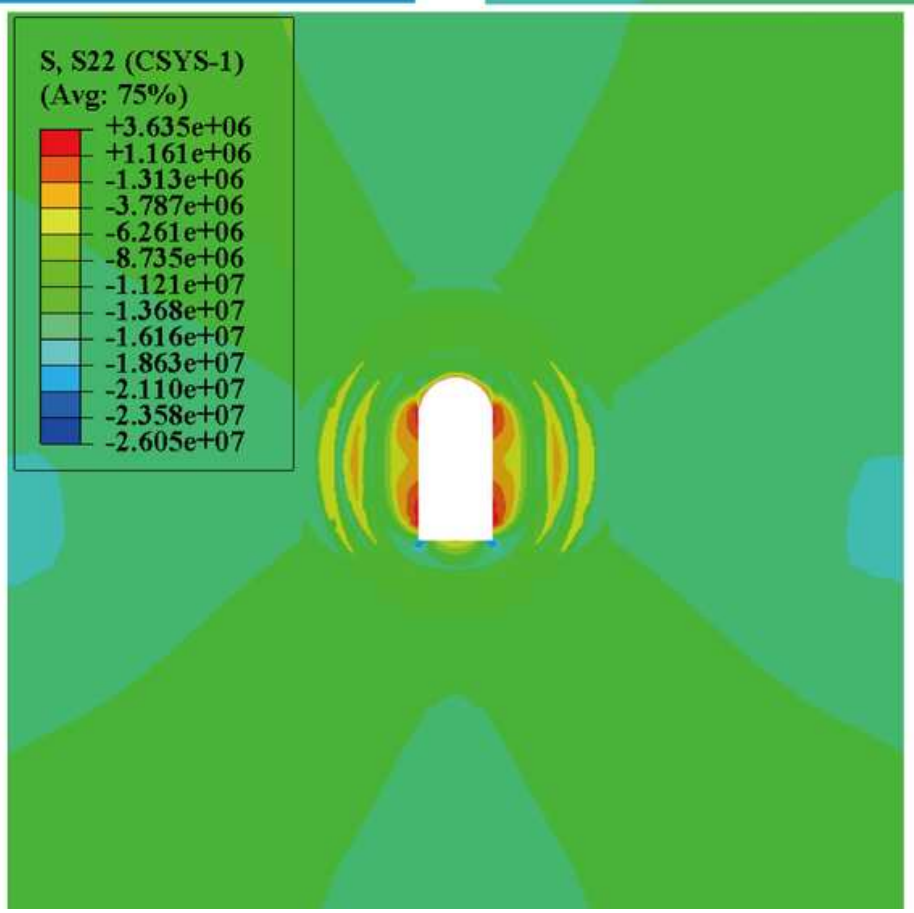

Figure 12

Simulation results in terms of the contour of: (a) Radial displacement; (b) Radial stress; and (c) Tangential stress in the surrounding rock of the cavern. 


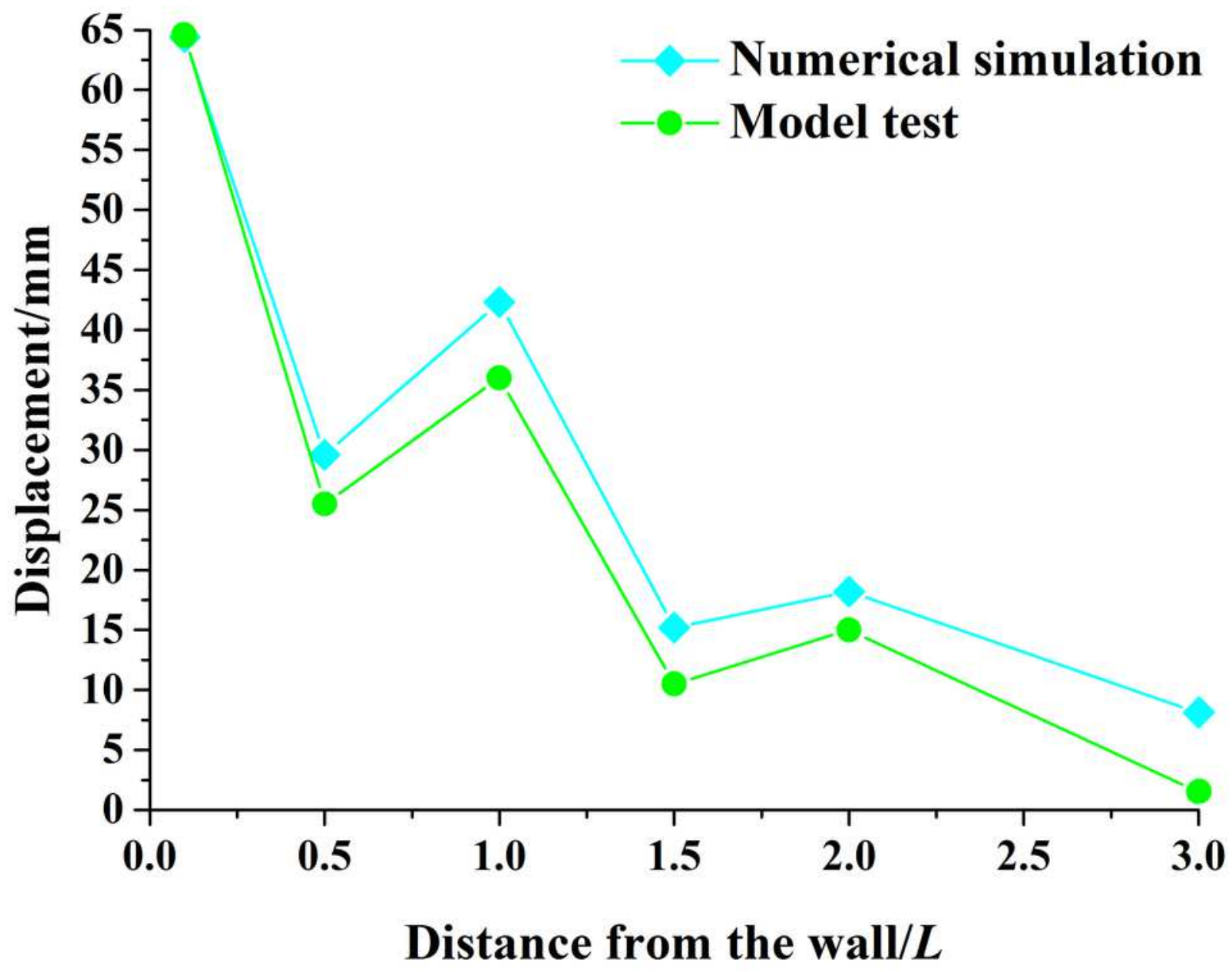

Figure 13

Comparison of the radial displacement of the cavern obtained from the geomechanical model test and the numerical simulation. 